\title{
Empirical Cost Estimation for U.S. Navy Ships
}

\author{
Johnathan Mun \\ Department of Information Science, Graduate School of Operational and Information Sciences, USA
}

Received September 10, 2019; Revised October 10, 2019; Accepted October 20, 2019

Copyright (C) 2019 by author, all rights reserved. Author agrees that this article remains permanently open access under the terms of the Creative Commons Attribution License 4.0 International License.

\begin{abstract}
This article pertains to the development of alternative ship cost modeling methodologies. Most ship cost modeling has been traditionally weight-based. This approach drives the U.S. Navy to select smaller ships that, consequently, require custom-designed shipboard components. This research project is intended to help determine if there is a more accurate way to empirically predict, forecast, and model ship cost. Current and forecasted U.S. Department of Defense budgets require identifying, modeling, and estimating the costs of shipbuilding. Information and data were obtained via publicly available sources and were collected, collated, and used in an integrated risk-based cost and schedule modeling methodology. The objective of this study is to develop a comprehensive cost modeling strategy and approach, and as such, notional data were used. Specifically, we used the Arleigh Burke Class Guided Missile Destroyer DDG 51 Flight I, Flight II, Flight IIA, and Flight III as a basis for the cost and schedule assumptions, but the modeling approach is extensible to any and all other ships within the U.S. Navy. The results will be used to develop recommendations and develop a cost modeling tool on how to implement ship cost forecasts. This example will provide a roadmap for other new ship cost modeling by the U.S. Navy, thereby improving effectiveness and increasing cost savings.
\end{abstract}

Keywords Parametric Cost Model, Cost Simulation, Ship Cost Estimation, Monte Carlo Simulation, U.S. Navy Ship Cost

\section{Introduction}

This research project pertains to the identification, review, and potential development of existing and alternative ship cost modeling methodologies. Most ship cost modeling has been traditionally weight-based. This approach drives the U.S. Navy decision makers to acquire smaller ships that require custom-designed shipboard components.
Current, and future, Department of Defense (DoD) acquisition budgeting processes require identifying, modeling, and estimating the costs of shipbuilding. The purpose of this research project is to determine if there is a more accurate way to empirically predict and model ship acquisition costs. The cost modeling tool developed in this study is intended to support development of ship cost forecasts. The proof of concept example for using this cost modeling tool included herein will provide a roadmap for other new ship acquisition cost modeling. The outcome of this research will likely increase cost savings.

The focus of this research is a comprehensive review of the most promising cost modeling methodologies. Notional cost data, or rough order of magnitude values, will be collected or generated to support this review of the cost methodologies. These "data" will be generated by the researchers using archival cost data from ship maintenance projects of various destroyer (i.e., DDG) acquisitions. We will identify these extrapolations, and we will use the resulting notional data to help evaluate the efficacy of the various cost models. This approach allows readers and study sponsors to see the various types of cost models, approaches, and sample data variables that are required to run the cost models and to examine sample results, as well as review the pros and cons of each approach. This study may require a follow-on project if there is a method that is of interest or that the sponsors feel might be applicable for a given ship acquisition context. The required data variables as well as sample results will be listed in the report, so the sponsors will know what to expect prior to engaging in any new research project. A follow-on study would allow us to obtain real-life cost data that could be plugged into the desired cost model.

The selected cost model will likely include the standard parametric models, nonparametric methods, and systems dynamics based on project management task-based schedule and cost models; semiparametric Monte Carlo simulation models; curve fitting, time-series, and cross-sectional models; nonlinear models; and so forth that have proven useful in forecasting costs in other acquisition contexts. 


\section{Literature Review}

In the NAVSEA Cost Estimation Handbook, the author provides a ready reference to "support the stewardship of our cost engineering capabilities" (Deegan, 2005), while Independent Cost Estimating Services by SPAR Associates (2015) "uses its system to quickly estimate ship costs based on initial design data and to provide the impact on costs of alternate design and build strategy decisions.”

Lee (2014) looked at improving the parametric method of cost estimating relationships of U.S. Navy ships. In considering recent military budget cuts, there has been a focus on determining methods to reduce the cost of U.S. Navy ships. According to Lee,

RAND National Defense Research Institute study showed many sources of cost escalation for Navy ships. Among them were included the characteristic complexity of modern Naval ships, which contributed to half of customer driven factors. This paper focuses on improving the current parametric cost estimating method used as referenced in NAVSEA's Cost Estimating Handbook.

Currently, as Lee (2014) describes,

Weight is used as the most common variable for determining cost in the parametric method because it's a consistent physical property and most readily available. Optimizing ship design based on weight may increase density and complexity because ship size is minimized.

That paper introduced "electric power density and outfit density as additional variables to the parametric cost estimating equation and will show how this can improve the early stage cost estimating relationships of Navy ships" (Lee, 2014).

From our literature survey, we found that there are four common types of cost estimating methods: "Analogy, Parametric, Engineering Build-up, and Extrapolation from Actuals" (Lee, 2014). During the very early stages of cost estimating, even before the concept refinement stage, the Analogy cost estimating method is used. As more details emerge and more information is available for the cost estimator, a more accurate, Build-up cost estimation is used. Toward the end of the ship's lifecycle, we can extrapolate actual cost information, and it is no longer an estimation.

NAVSEA (Naval Sea Systems Command [NAVSEA], 2015) released instructions regarding the preparation of government cost estimates. The general methods described in the manual include the four most common methods of cost estimating: "roundtable, comparison, detailed estimating, and parametric cost estimating (cost estimate relationships)."

In his article, "Budget Office Questions Navy Shipbuilding Cost Estimates,” Walcott (2012) finds that the U.S. Navy is

underestimating the cost of its proposed 30-year shipbuilding program by 19 percent, the non-partisan Congressional Budget Office said in a report. By comparison, using its own models and assumptions, CBO estimates that the cost for new-ship construction under the 2013 plan would average \$20.0 billion per year, or a total of $\$ 599$ billion through 2042.

In Integrating Cost Estimating with the Ship Design Process, Deschamps and Greenwell (2009) explain that the ship design process is an

evolutionary process where at the conceptual design level, pre-Milestone A for Naval acquisition programs, few details are known, and the metrics used for estimating costs are based on analogous platforms and limited parametric functions. As the design process continues towards Milestone B the design begins to take shape with fewer analogies and an increasing number of parametric cost drivers. At this point, $80 \%$ of the life cycle costs (LCC) are set and the cost risk associated with the design becomes an important piece of the overall acquisition costs. It is imperative that the methods used to estimate the cost and cost risk are tightly coupled with the design iteration process and are parametric in nature in order to support the needs of the Program Manager in terms of not only the basic design but design trade-offs.

The authors present the use and benefits of employing a set of parametric cost models during the concept and preliminary phases of ship design.

These cost models produce quick assessments of costs and risk, for design and mission trade-off alternatives. The cost models, being parametric, can follow the evolutionary design process. At early stages of the design, when many details of the design are not yet available, the cost models automatically provide statistically synthesized values for missing parameters. Then, as the design matures, these default values can be replaced with values developed for the design. (Deschamps \& Greenwell, 2009)

In A Practical Approach for Ship Construction Cost Estimating, Ross (2002) states that to succeed commercially, shipyards must be able to accurately estimate costs. Cost estimating is necessary for the "bid process, change orders, and trade-off studies." Numerous cost-estimating approaches exist. They are based on extrapolations from "previously-built ships, detailed bottoms-up parametric models, and integrated physics-based analyses." Cost estimating can be frustrating to shipyard personnel. Cost estimators may lack timely technical information and face data inconsistencies.

Ship engineers and naval architects commonly lack feedback on the cost consequences of their technical decisions. Managers often lack information denoting the level of confidence in cost estimates upon which they must make business decisions. Finally, many approaches to cost estimating are mysterious and not formally validated (each cost estimator has his own black book), complicated (too time consuming to be of use to decision 
makers), or difficult to use (steep learning curve). (Ross, 2002)

This paper presents an approach that enables instant sharing of cost and technical data among ship engineers, naval architects, and cost estimators; the analysis was meant to provide confidence measures to managers.

Truver (2001) believes that estimating ship construction costs is behind the times. In one highly critical area of naval analysis, the U.S. Navy seems to be "bogged down in the early years of the last century.” The U.S. Navy's traditional approach and methodology for estimating the construction and lifecycle costs of new ships is "out of step with the Revolution in Business Affairs.” According to Truver (2001):

The Naval Surface Warfare Center (NSWC) is rethinking the current paradigm of ship cost estimating. Taking the lead in a joint Navy-industry initiative to reinvent the way ship costs are determined, they have developed the Product Oriented Design and Construction (PODAC) Cost Model.

Since the end of the Cold War, naval procurement for the U.S. Navy has seen a dramatic decrease. This decrease in defense spending has placed existing programs under more scrutiny than previous years. As a result, there is less tolerance on the part of taxpayers and U.S. Congress for procurement cost growth. (Miroyannis, 2006)

The research attempts to examine the current method that the U.S. Navy uses to conduct ship cost estimates, and it suggests changes in order to improve the confidence level and accuracy of the forecasts. An examination of how industry is conducting cost estimates was used as a comparison to the current U.S. Navy practices. Finally, using only a weight-based approach to ship cost estimating is insufficient. It is necessary to develop and use a model that incorporates other cost driving factors in order to develop estimates of sufficient quality at the preliminary design level (Miroyannis, 2006).

Smith (2008) updates one ship cost estimation model by combining the two existing models (the Basic Military Training School [BMTS] Cost Model and the MIT Math Model) in order to develop a program that can accurately determine both a ship's acquisition cost as well as its life cycle cost. Using United States Coast Guard resources, this project addressed various aspects of the ship design process that have a direct effect on the cost of building a ship. This will include, but not be limited to, the cost estimation process, determining which design decisions have the biggest impact on the ship's total cost, common pitfalls in the design process that lead to increases in cost, and lessons learned that have helped minimize the cost of a ship.

Sullivan (2011) found that the inability to predict ship acquisition cost accurately is a great impediment to budget formulation and execution for shipbuilding programs. It also has eroded the U.S. Navy's credibility with Congress.
Dramatic improvements in cost analysis tools are needed. Areas for improvement include the following:

- Prediction of R\&D costs based on system complexity, subsystem technology, and state of development

- Modeling of design and construction workforce requirements

- 10 Naval Ship Designs and Construction;

- Topics for the Research and Development Community

- Modeling the cost of design tools, including configuration, mass properties tools

- $\quad$ Product Logistics Models environment

- Modeling of ship integration and test costs

- Assessment of the costs of facilitation of prime shipbuilding contractor, principal subcontractors, and warfare system contractors

- Modeling of the effects of concurrent workloads from multiple contracts at all contractors' facilities

- Assessment of cost of government warfare center participation in development and execution

- Probabilistic cost analysis tools that give the range of estimates and the probability that the estimates will not be exceeded (Sullivan, 2011)

Cost estimating tools could benefit from an approach that takes advantage of the massive computing power available today, and also the availability of highly intelligent search engines. The principle should be that if cost data exist anywhere, the U.S. Navy should be able to access them. This means that the cost of any component or commodity could theoretically be queried, stored in the navy-shipbuilder cost database, and periodically updated, either from catalog information, bid pricing, or other publicly available information. The U.S. Navy should, according to Sullivan,

adapt one or more of the commercially available search engines for this purpose and mandate its use for all shipbuilding programs. Furthermore, if shipbuilders could continue to execute the Common Parts Catalog initiative of the National Shipbuilding Research Program (NSRP), the search engines could query this catalog for component cost tabulation. (Sullivan, 2011)

Moore and White (2005) used a regression approach for estimating procurement costs:

Cost growth in Department of Defense weapons systems continues to be a scrutinized area of concern. One way to minimize unexpected cost growth is to derive better and more realistic cost estimates. In this vein, cost estimators have many analytical tools to ply. Previous research has demonstrated the use of a two-step logistic and multiple regression methodology to aid in this endeavor. We investigate and expand this methodology to cost growth in procurement dollar accounts for the Engineering and Manufacturing Development phase of DOD acquisition. We develop and present two salient statistical models for cost estimators to at least consider if not use in mitigating cost growth for existing and future 
government acquisition programs.

According to Brown and Neu (2008), engineering cost models must be reliable, practical and sensitive to the cost and performance impact of producibility enhancements. A baseline surface combatant cost model was developed using a modified weight-based approach. A more flexible model will be developed in Phase 2 using ACEIT (Automated Cost Estimating Integrated Tools). ACEIT is an automated architecture and framework for cost estimating. It is a government-developed tool that has been used to standardize and simplify the Life Cycle Cost estimating process in the government environment. Core features include a database to store technical and (normalized) cost data, a statistical package specifically tailored to facilitate cost estimating relationship (CER) development, a spreadsheet that promotes structured, systematic model development, and built-in government-approved inflation, learning, time phasing, documentation, sensitivity/what-if, risk, and other analysis capabilities. Our task will be to adapt this general framework for concept development naval ship cost analysis including producibility.

The Joint Agency Cost Schedule Risk and Uncertainty Handbook (Cost Assessment Data Enterprise [CADE], 2014) states that the government cost analysis community recognizes the need to

capture the inherent uncertainty of acquisition programs into realistic cost estimates to support the milestone decision process. Programmatic, cost, schedule, and technical uncertainties are present from the earliest concept exploration phase, through system development, acquisition, deployment, to operational and sustainment. Many estimating processes have focused on producing a single, discrete dollar value that in turn becomes the budget. Realistically, estimating processes develop a range of likely values, with objective and quantifiable analysis of uncertainty intrinsically embedded. The goal of this handbook is to introduce industry best practices for incorporating uncertainty into our estimates in order to provide decision makers with the information necessary to make sound, defendable investment decision.

This handbook emphasizes the need to shift away from estimates based solely on the best-guess of system and programmatic parameters and encourages the cost analyst to build models that address technical, programmatic, cost and schedule uncertainties, and risks as interdependent, not separate, processes. The effective incorporation of risk uncertainty in cost and schedule estimates is a challenging task. This handbook is promulgated to help establish a systematic, structured, repeatable, and defendable process for delivering comprehensive estimates to Government leadership to get the best possible capability with increasingly limited available resources. (CADE, 2014)

Cost estimating in the Naval Sea Systems Command "requires accurate costs estimates as it is critical to achieving an affordable U.S. Navy shipbuilding program" (Deegan and Mondal, 2008), who go on to say:

There is significant concern, both within and outside the Department of Defense, over the future affordability of the U.S. Navy's shipbuilding programs. The increasing costs of these programs reflect a variety of factors, such as lower production quantities, increasing weapons system complexity, increasing commodity prices, and a shortage of skilled workers in the shipbuilding industry. This article examines the challenges one faces when attempting to accurately predict future ship and weapons system costs. It also summarizes current initiatives under way within the cost engineering organization of the Naval Sea Systems Command (NAVSEA) to mitigate these challenges. Reliable cost estimates are important to maintaining a viable Navy. It is encouraging to see greater importance accorded to independent cost estimating within the DON along with efforts to understand and use quantitative risk analysis in making cost decisions. NAVSEA cost estimators are proud to be leaders in this endeavor. (Deegan \& Mondal, 2008)

Mulligan (2008) states that:

the accepted method for estimating ship construction and operating costs is due to Harry Benford, a professor of naval architecture and marine engineering at the University of Michigan, and dates from the 1960s. Benford conducted regression studies with a variety of technical and cost parameters to arrive at basic algebraic relationships among cargo capacity, ship dimensions, degree of streamlining (block coefficient), design operating speed, Admiralty coefficient, required shaft horsepower, required engine size, and ship steel weight. His approach however is based on design assumptions which have grown increasingly less applicable.

\section{This research presents new}

models for estimating new building costs, based on recent 2003-2007 data. This dataset reflects contemporary ship design and construction practices, and recent cost trends. The models can be used as a basis for economic analysis whenever newbuilding ship cost is considered as an alternative. Though not making an abrupt break with accepted practice, the cost equations presented above offer various advantages for shipping economists and strategic planners. Estimating newbuilding costs with these models captures recent practical experience and cost trends facing the industry in the past few years. (Mulligan, 2008)

Applications of known data mining algorithms to the problem of estimating the cost of ship development and construction was conducted. According to Kaluzny et al. (2011), the work is a product of

North Atlantic Treaty Organization Research and Technology Organization Systems Analysis and Studies 076 Task Group, in a blind, ex post exercise, the Task 
Group set out to estimate the cost of a class of Netherlands' amphibious assault ships, and then compare the estimates to the actual costs (the Netherlands Royal Navy withheld the actual ship costs until the exercise was completed). Two cost estimating approaches were taken: parametric analysis and costing by analogy. For the parametric approach, the M5 system (a combination of decision trees and linear regression models) of Quinlan (1992). Agglomerative hierarchical cluster analysis and nonlinear optimization was used for cost estimation by analogy approach void of subjectivity.

The review of standard forecasting logic, in what follows, is useful in understanding the foundations of the various cost modeling techniques assessed in this study. Generally, forecasting can be divided into quantitative and qualitative approaches. Qualitative forecasting is used when little to no reliable historical, contemporaneous, or comparable data exist. Several qualitative methods exist such as the Delphi or expert opinion approach (a consensus-building forecast by field experts, marketing experts, or internal staff members), management assumptions (target growth rates set by senior management), as well as market research or external data or polling and surveys (data obtained through third-party sources, industry and sector indexes, or active market research). These estimates can be either single-point estimates (an average consensus) or a set of prediction values (a distribution of predictions). The latter can be entered into the Risk Simulator software tool, used in this study, as a custom distribution and the resulting predictions can be simulated, that is, running a nonparametric simulation using the prediction data points as the custom distribution. This approach can leverage experts' knowledge by combining it with available quantitative data to arrive at more reliable shipbuilding cost estimates.

Expert knowledge can be leveraged using the software by including qualitative estimates with quantitative analysis techniques. We provide several ship cost modeling case examples that are designed to demonstrate how the various cost modeling tools can be used in estimating shipbuilding costs and that will also be helpful in learning how to apply the Risk Simulator software to develop more robust shipbuilding cost estimates. The Appendix provides a quick review of the quantitative methodologies that are available in the software.

\section{Case Application: DDG 51 FLT III}

This section provides a detailed illustration of the proposed integrated cost estimation modeling approach. As this is only an illustration, and due to a lack of proprietary data for this first phase of the analysis, the input assumptions are only high-level approximations based on publicly available information and publicly available subject matter expert estimates. Therefore, the results generated are not designed to be used in any specific decision making. Nonetheless, the approach presented has proven to be robust and valid, and with the correct input assumptions, can be rerun to generate accurate and reliable ship cost estimates. Information and data were obtained via publicly available sources and were collected, collated, and used in an integrated risk-based cost and schedule modeling methodology. The objective of this case study was to develop a comprehensive cost modeling strategy and approach, and, as such, notional data were used. Specifically, we used the Arleigh Burke Class Guided Missile Destroyer DDG 51 Flight I, Flight II, Flight IIA, and Flight III (Figure 1) as a basis for the cost and schedule assumptions, but the modeling approach is extensible to all other shipbuilding cost contexts within the U.S. Navy. 


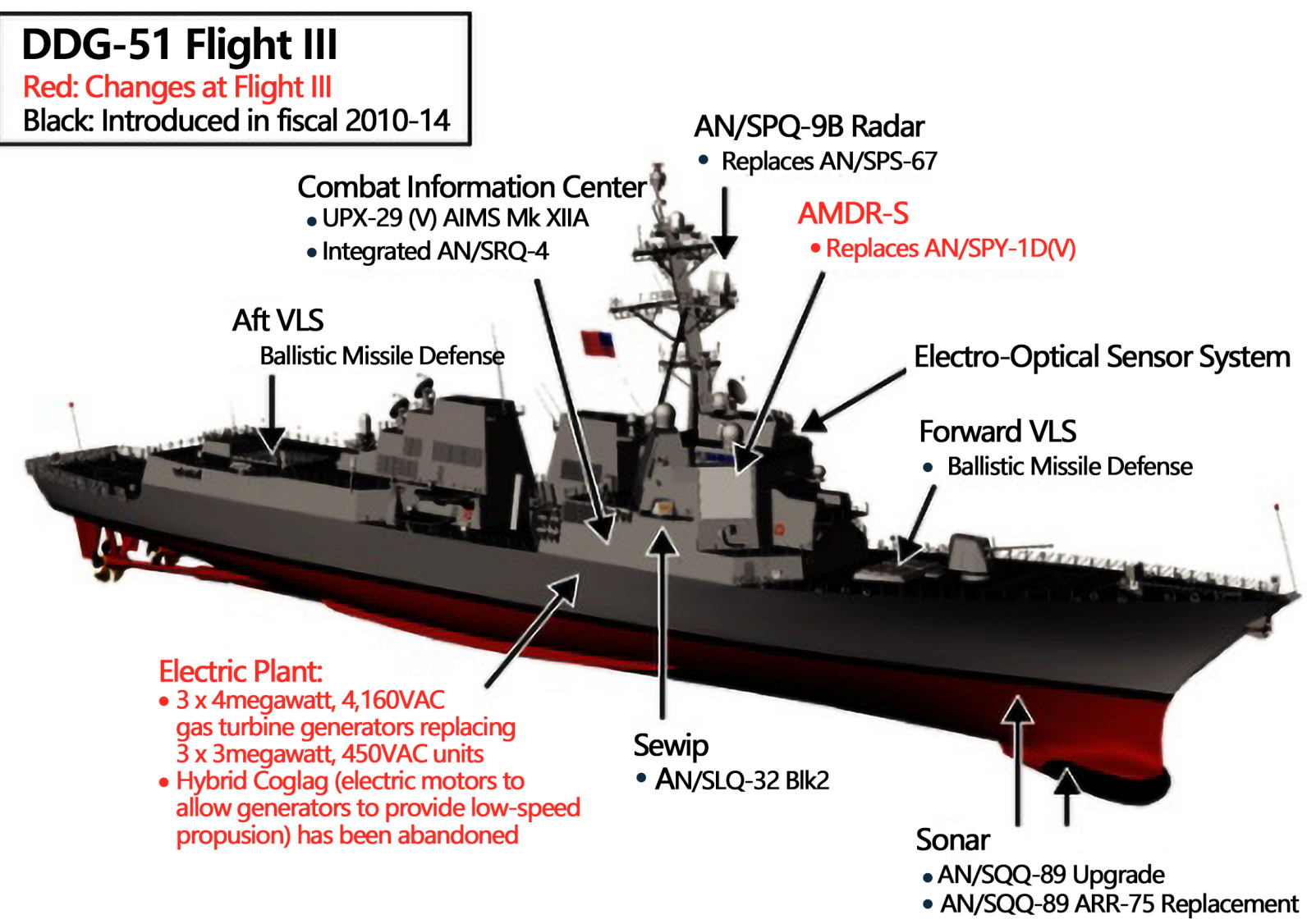

Figure 1. Overview of DDG 51 Flight III

\subsection{DoD Spending on the Aegis Destroyer in FY 2012-2014}

Figure 2 shows some sample acquisition budgets for DDG 51 Aegis destroyers from FY 2012 through FY 2016. The comprehensive DoD budget was downloaded and analyzed in the current research.

\begin{tabular}{|c|c|c|c|c|c|c|c|c|c|c|c|c|}
\hline \multirow{3}{*}{ DDG 51 AEGIS Destroyer } & & \multicolumn{2}{|c|}{ ACTUAL } & \multicolumn{2}{|c|}{ ACTUAL } & \multicolumn{2}{|c|}{ ACTUAL } & \multicolumn{2}{|c|}{ PRELIMIIIARY } & \multicolumn{3}{|c|}{ REQUESTED } \\
\hline & & \multicolumn{2}{|c|}{ FY2012 Total } & \multicolumn{2}{|c|}{ FY2013 Total } & \multicolumn{2}{|c|}{ FY2014 Total } & \multicolumn{2}{|c|}{ FY2015 Total } & \multicolumn{2}{|c|}{ FY2016 Total } & \\
\hline & & QTY & Million S & QTY & Million \$ & QTY & Million \$ & $Q T Y$ & Million S & QTY & Million \$ & \\
\hline Shipbuilding \& Conversion & NAVY & 1 & $2,081.43$ & 3 & $4,497.01$ & 1 & $1,985.12$ & 2 & $2,795.95$ & 2 & $3,149.70$ & 产芯 \\
\hline Ship Modifications & NAVY & & 126.37 & & 407.71 & & 285.99 & & 324.22 & & 364.16 & \\
\hline Completion Costs & NAVY & & - & & - & & 100.00 & & 129.14 & & - & 要畗 \\
\hline Outfitting \& Post Delivery & NAVY & & 49.10 & & 7.30 & & 1.30 & & 6.50 & & 62.10 & \\
\hline Total Procurement & & 1 & $2,256.91$ & 3 & $4,912.02$ & 1 & $2,372.41$ & 2 & $3,255.81$ & 2 & $3,575.96$ & 总 \\
\hline RDT\&E (Hybrid Electric Drive) & NAVY & & - & & - & & & & 7.95 & & 4.22 & \\
\hline Total RDT\&E & & & & & - & & & & 7.95 & & 4.22 & \\
\hline Total Program Spending & & 1 & $2,256.91$ & 3 & $4,912.02$ & 1 & $2,372.41$ & 2 & $3,263.76$ & 2 & $3,580.18$ & \\
\hline
\end{tabular}

Download Official U.S. Department of Defense (DoD) Budget Data:

Shipbuilding \& Conversion | DDG-51 AEGIS Destroyer

Figure 2. DoD Spending and Procurement for FY 2012-2014 


\subsection{High-Level Shipbuilding Process}

Figure 3 shows the high-level process flow of building ship hulls and sections.

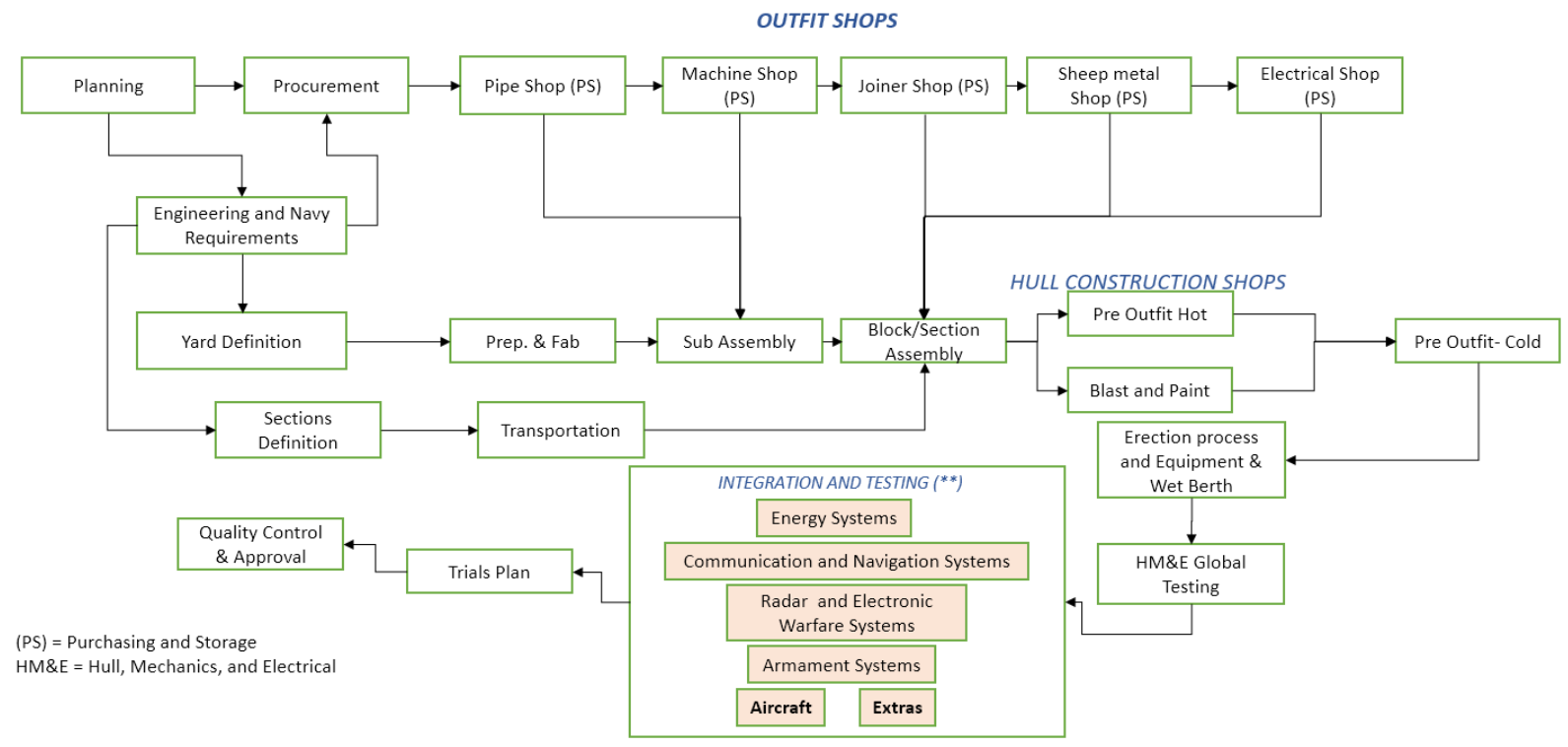

Figure 3. High-Level Process Flow (Hull and Sections)

\subsection{Information, Communication, and Technology Subprocess}

Figure 4 shows the ship's subprocess for information, communication, and technology (ICT).

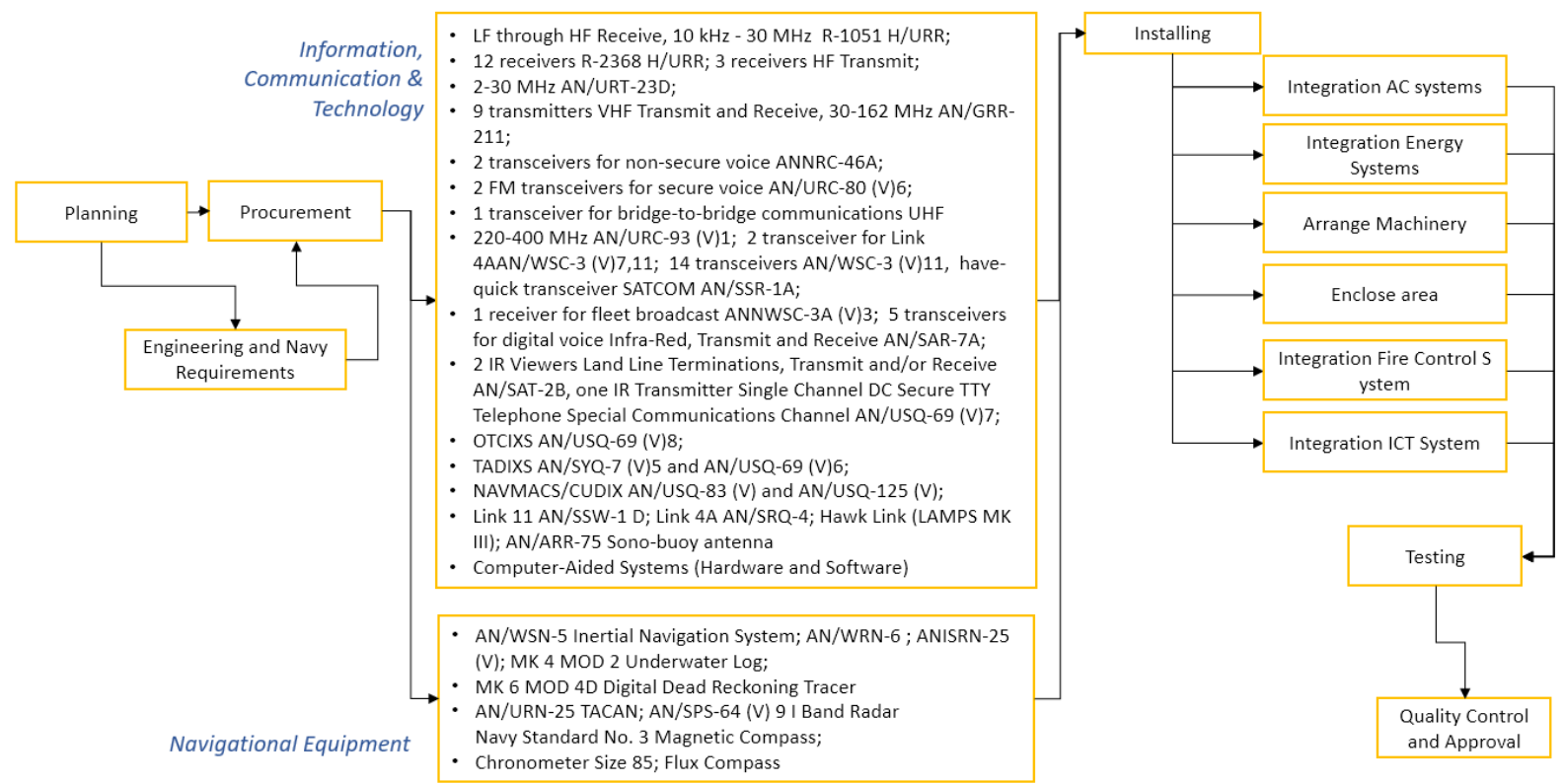

Figure 4. Subprocess for Information, Communication, and Technology (ICT) 


\subsection{Weapons System Subprocess}

Figure 5 shows the ship's subprocess for weapons systems.

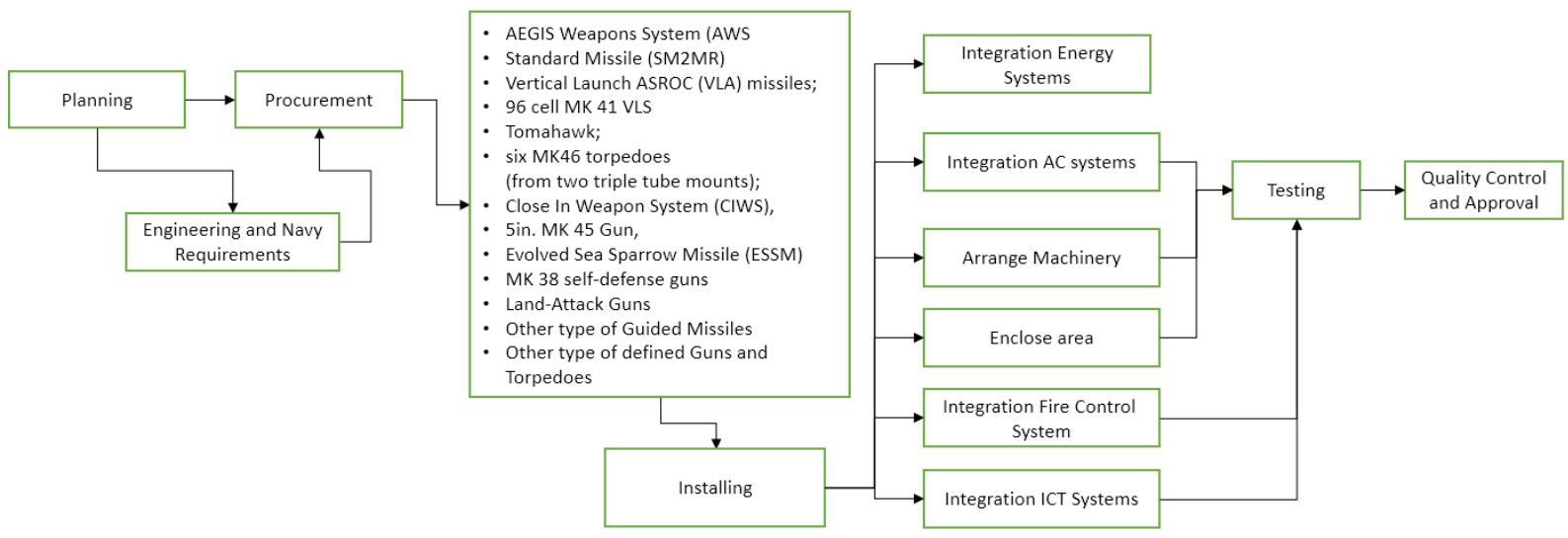

Figure 5. Subprocess for Weapons Systems

\subsection{SPY-6 Radar System}

Figure 6 shows the ship’s radar subsystem’s process.

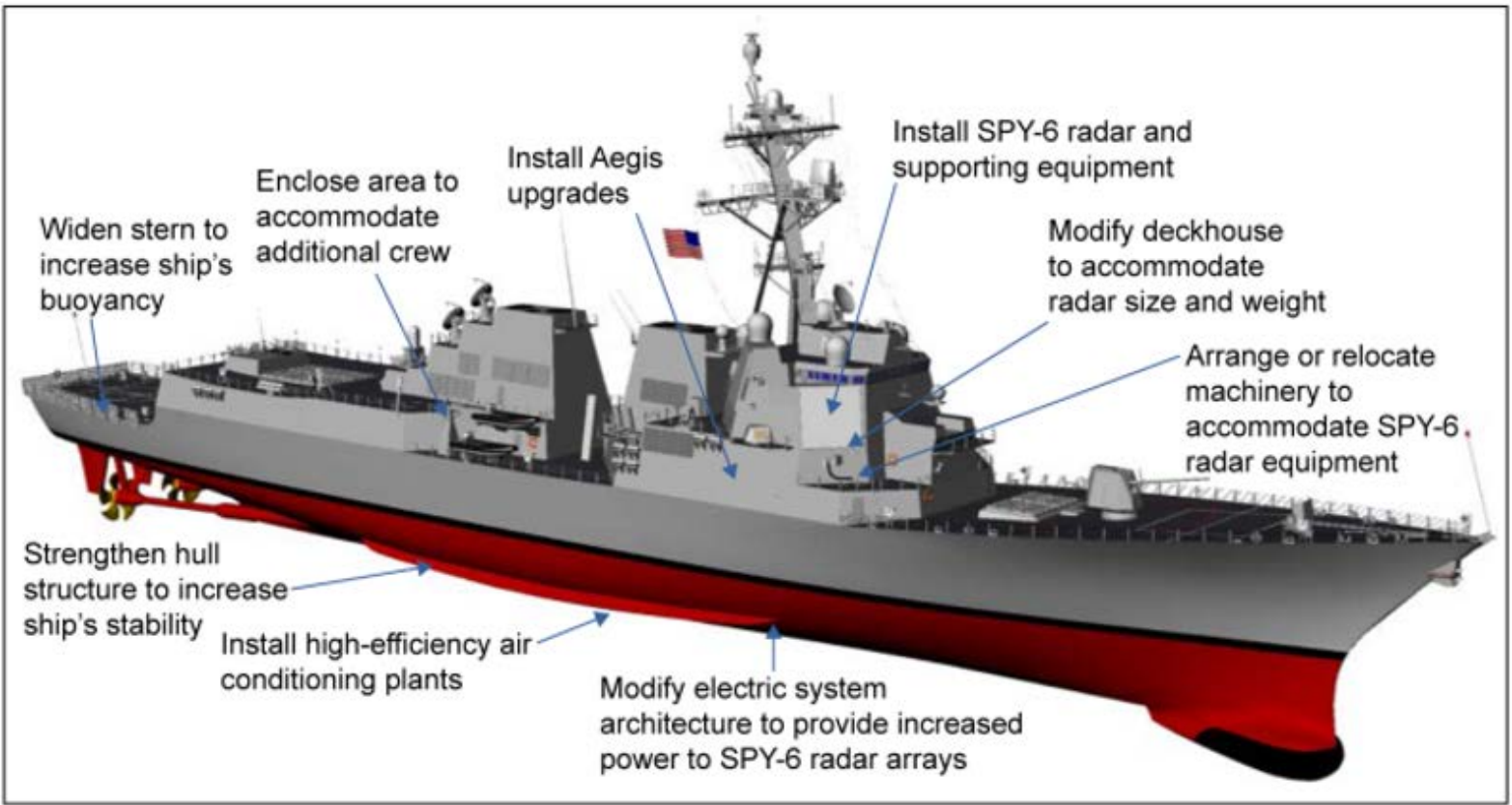

Source: GAO (analysis); Navy (image and data). I GAO-16-613

ARLEIGH BURKE DESTROYERS:

Delaying Procurement of DDG 51 Flight III Ships Would Allow Time to Increase Design Knowledge GAO-16-613: Published: Aug 4, 2016. Publicly Released: Aug 4, 2016.

\section{What GAO Found}

The Air and Missile Defense Radar (AMDR) program's SPY-6 radar is progressing largely as planned, but extensive development and testing remains. Testing of the integratec SPY-6 and full baseline Aegis combat system upgrade-beginning in late 2020-will be crucial for demonstrating readiness to deliver improved air and missile defense capabilities to the first DDG 51 Flight III ship in 2023. After a lengthy debate between the Navy and the Department of Defense's (DOD) Director of Operational Test and Evaluation, the Secretary of Defense directed the Navy to fund unmanned self-defense test ship upgrades for Flight III operational testing, but work remains to finalize a test strategy.

Figure 6. SPY-6 Radar System and Rework 


\subsection{DoD Extras: Electronic Warfare, Decoys, Extra Capabilities}

Figure 7 shows the ship’s Electronic Warfare, Decoys, and Extra Capabilities subprocesses.

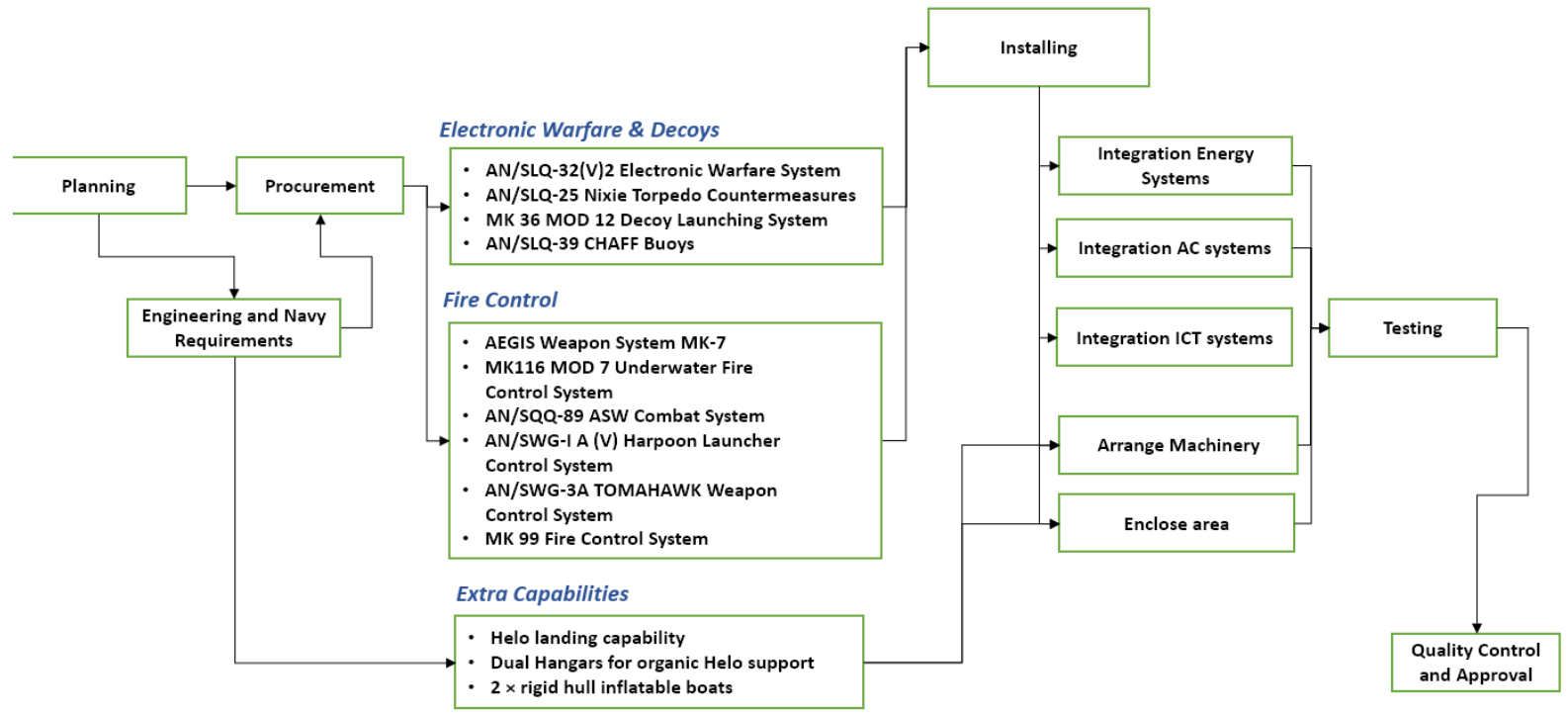

Figure 7. Subprocesses and Examples of DoD Extras

\section{Risk-Based Schedule and Cost Process Modeling}

Figures 8 illustrates how the project management tasks are incorporated into the Project Economics Analysis Toolkit (PEAT) software application. It includes all the high-level tasks required to build the ship along with their attendant costs with one million simulation trials that provide the possible distributions of the costing data. The parallel development of tasks $20-25$ is where the ship's various subsystems are incorporated into the cost and schedule model.

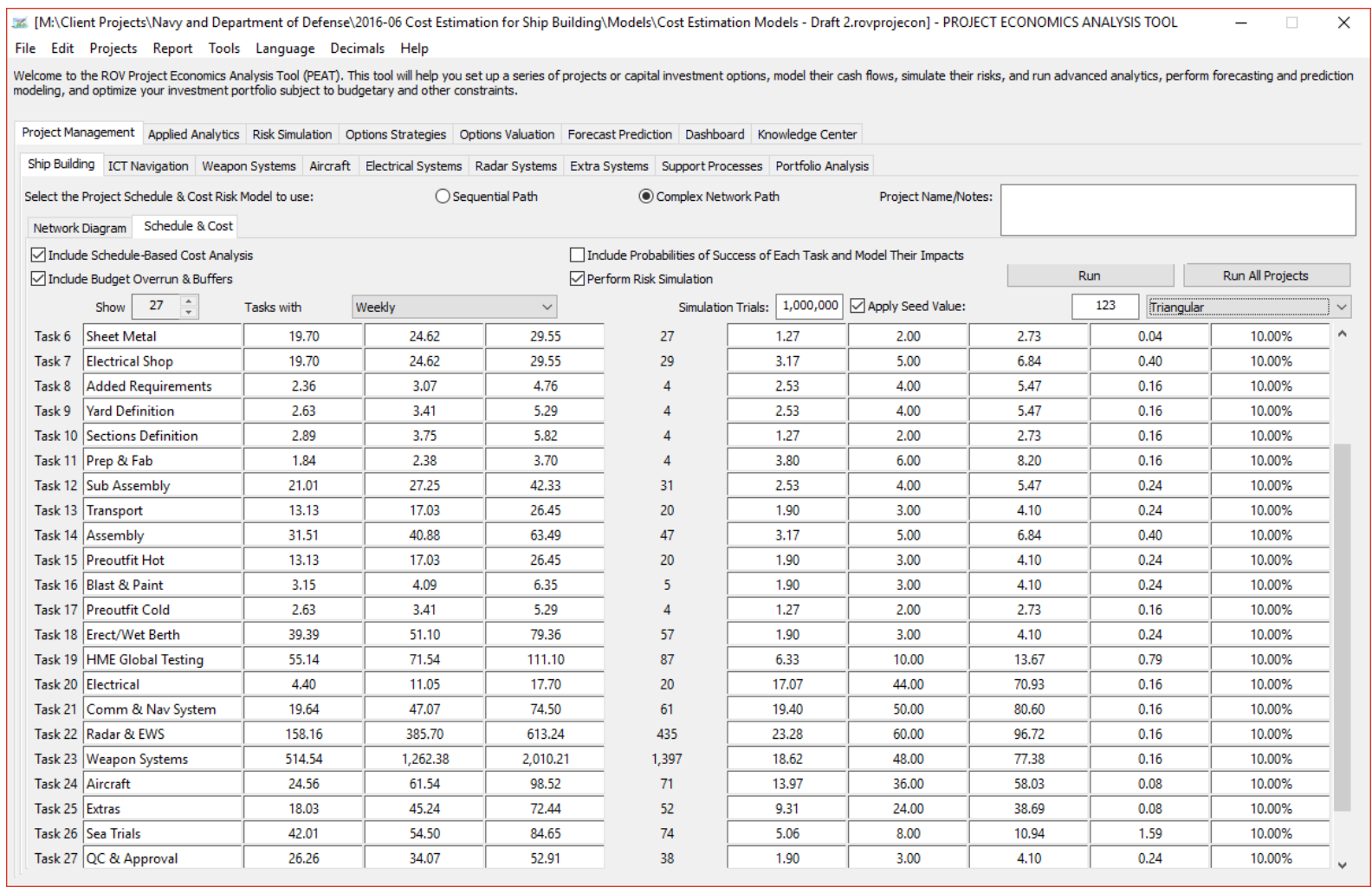

Figure 8. Input Assumptions 
Similarly, using the cost and schedule modeling approach, we can zoom into various tasks and model each task in more detail. This permits us to use the results by reinserting the more detailed data values back into the more comprehensive model as required to improve accuracy. For instance, Figure 9 shows the ship's weapons subsystem, with Figure 10 showing its cost and schedule assumptions (Figure 5).

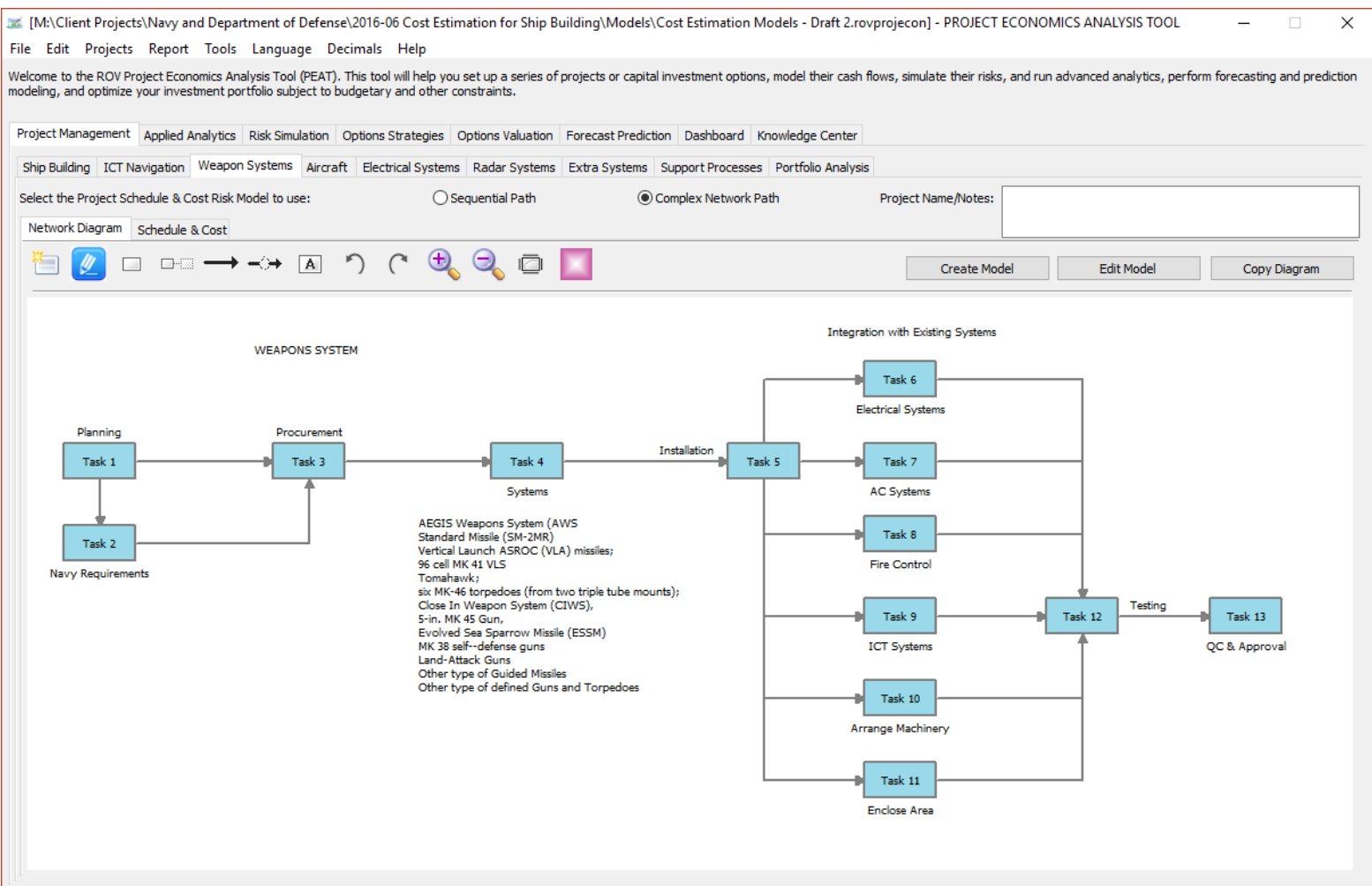

Figure 9. Weapons Subsystem Process Development

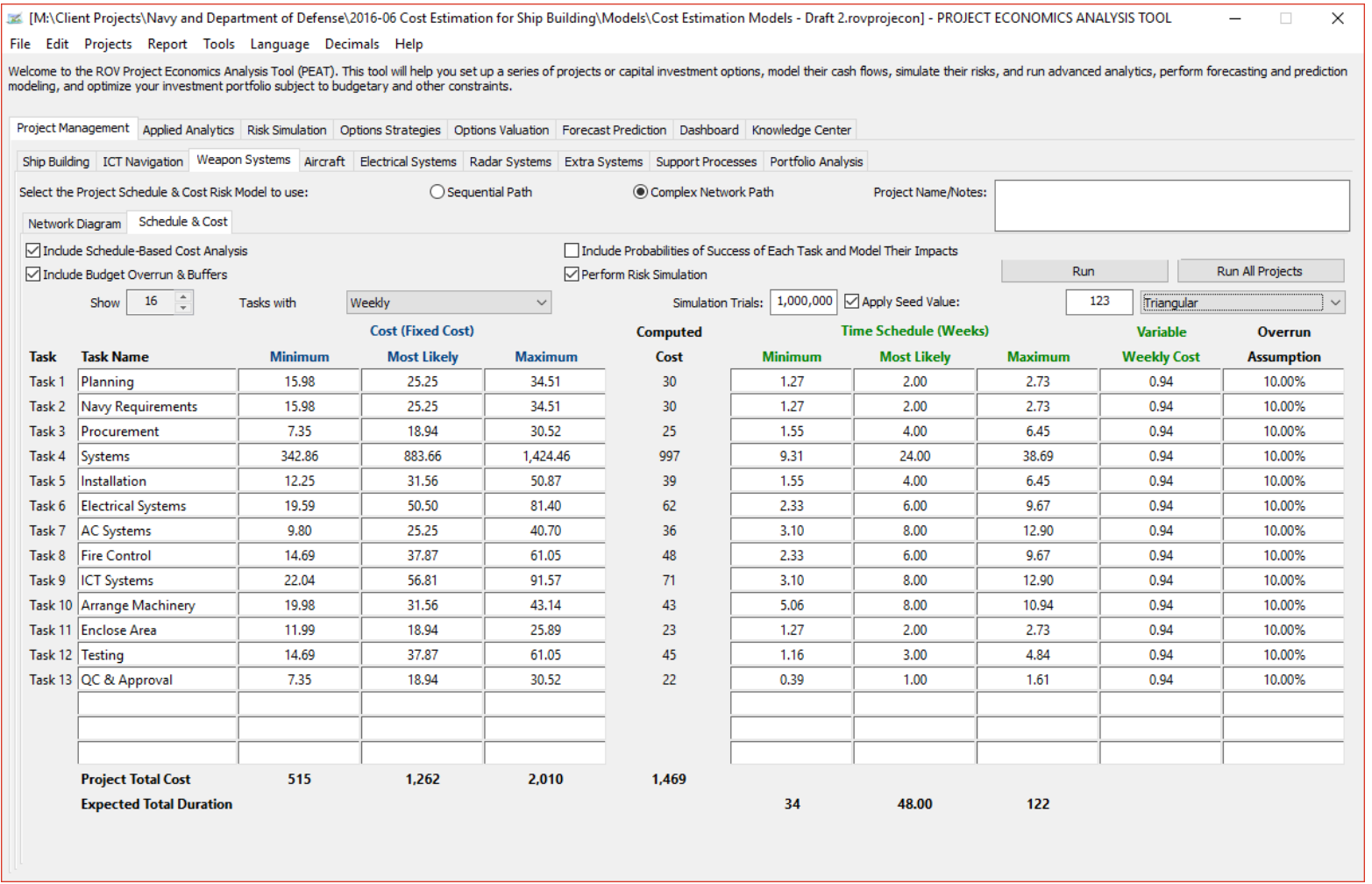

Figure 10. Weapons Subsystem Cost and Schedule Assumptions 


\subsection{Critical Success Factors in Cost and Schedule Estimates}

Tornado analysis is a powerful analytical tool that captures the model's sensitivity to fluctuations in the critical success factors values for cost and schedule. This is done by identifying the static impacts of each variable on the outcome of the model; that is, the tool automatically perturbs each variable in the model a preset amount, captures the fluctuation on the model's forecast or final result, and lists the resulting perturbations ranked from the most significant to the least. Figures 11 and 12 illustrate the application of a tornado analysis. Tornado analysis answers the question: "What are the critical success drivers that affect the model's output the most?"

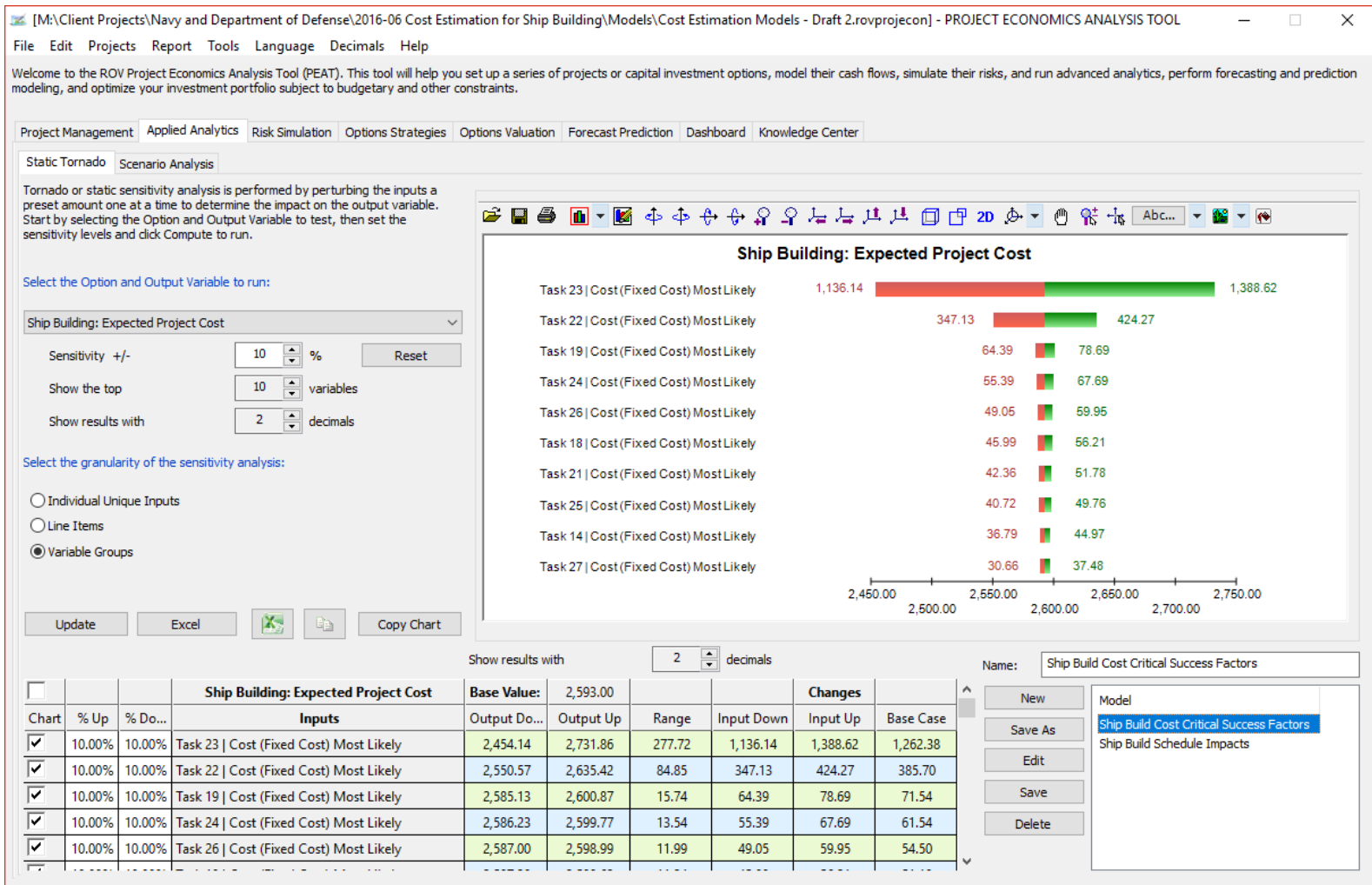

\begin{tabular}{|c|c|c|c|c|c|c|c|c|c|c|c|}
\hline \multirow[b]{2}{*}{$\Gamma$} & & & & \multicolumn{2}{|c|}{ Show results with } & \multicolumn{2}{|c|}{$2 \div$ decimals } & & & Name: & Ship Build Cost Critical Success Factors \\
\hline & & & Ship Building: Expected Project Cost & Base Value: & $2,593.00$ & & & Changes & & New & Model \\
\hline Chart & $\%$ Up & \% Do... & Inputs & Output Do... & Output Up & Range & Input Down & Input Up & Base Case & & Ship Build Cost Critical Success Factors \\
\hline$\sqrt{v}$ & $10.00 \%$ & $10.00 \%$ & Task 23 | Cost (Fixed Cost) Most Likely & $2,454.14$ & $2,731.86$ & 277.72 & $1,136.14$ & $1,388.62$ & $1,262.38$ & Save As & Ship Build Schedule Impacts \\
\hline$\overline{\sqrt{v}}$ & $10.00 \%$ & $10.00 \%$ & Task 22 | Cost (Fixed Cost) Most Likely & $2,550.57$ & $2,635.42$ & 84.85 & 347.13 & 424.27 & 385.70 & Edit & \\
\hline$\sqrt{v}$ & $10.00 \%$ & $10.00 \%$ & Task $19 \mid$ Cost (Fixed Cost) Most Likely & $2,585.13$ & $2,600.87$ & 15.74 & 64.39 & 78.69 & 71.54 & Save & \\
\hline$\sqrt{\sqrt{V}}$ & $10.00 \%$ & $10.00 \%$ & Task 24 | Cost (Fixed Cost) Most Likely & $2,586.23$ & $2,599.77$ & 13.54 & 55.39 & 67.69 & 61.54 & Delete & \\
\hline$\overline{\sqrt{V}}$ & $10.00 \%$ & $10.00 \%$ & Task 26 | Cost (Fixed Cost) Most Likely & $2,587.00$ & $2,598.99$ & 11.99 & 49.05 & 59.95 & 54.50 & & \\
\hline
\end{tabular}

Figure 11. Tornado Analysis of Critical Success Factors (Cost Factors) 


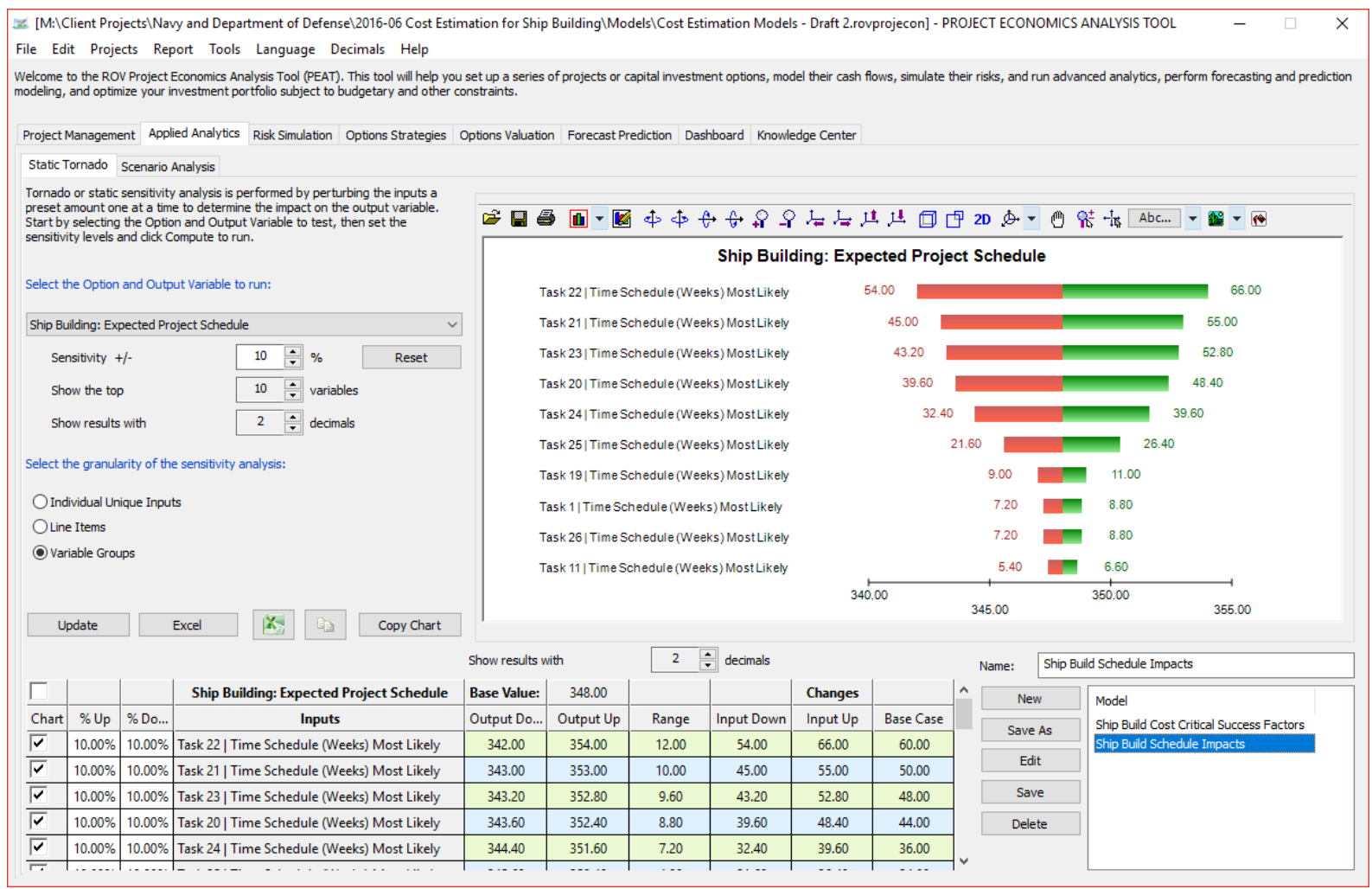

Figure 12. Tornado Analysis of Critical Success Factors (Schedule Factors)

\subsection{Risk-Based Schedule and Cost Process Simulation}

Next, the Monte Carlo Risk Simulation capability of the tool was used to create artificial futures by generating hundreds of thousands of sample paths of outcomes and analyzing their prevalent characteristics. In the Monte Carlo simulation process, triangular distributions (i.e., best-case, most-likely case, and worst-case scenarios) were used on the previously identified critical inputs. Figure 13 shows the values for a sample distributional spread used in Monte Carlo Risk Simulations per the Air Force Cost Analysis Handbook (AFCAH). These probability spreads were applied to each of the task's cost and schedule inputs, and each of the tasks was simulated tens of thousands to hundreds of thousands of trials.

Figure 14 shows a sample representation of the results from the simulation process. For instance, the figure shows a $90 \%$ confidence interval for the total acquisition cost of a full-complement ship (fully built ship delivered after tests and sea trials, complete with ICTS, weapons systems, electrical systems, SPY-6 radar, and other add-ons). The $90 \%$ confidence interval pegs the total acquisition costs to be between $\$ 2.0$ billion and $\$ 3.2$ billion for a single ship. Clearly, these results are only for illustration purposes and are not meant to be definitive. Figure 15 shows the probability that there will be a budget overrun. For instance, if the acquisition budget is $\$ 2.2$ billion, then we see that there is an approximately $12 \%$ probability of the cost coming in at or under budget, which means that there is an $88 \%$ probability of a budget overrun, with a mean or average actual acquisition cost of $\$ 2.6$ billion.

Similarly, Figure 16 shows the total schedule from the initial contracting phase to delivery of the ship, complete with all subsystems installed and tested. The 90\% confidence interval pegs the total schedule at between 110 and 146 weeks, averaging at 127 weeks.

Alternatively, the modeling approach allows us to look at the ship's subsystems. For example, Figure 17 shows the $90 \%$ confidence interval for weapons systems costs ( $\$ 1.1$ to $\$ 1.8$ billion), while Figure 18 shows modeling the cost of building the ship without any subsystems. Each individual system or combinations of systems can be similarly modeled and analyzed (Figure 19), or overlaid on one another, as shown in Figures 20, 21, and 22. The probability distributions in these three figures allow you to compare how one system's cost and uncertainties compare to one another. Finally, Figure 23 shows how the individual task's schedule and cost elements impact and are correlated to each other, by way of dynamic sensitivity analysis. 
U.S. Air Force Cost Analysis Handbook (AFCAH)

\begin{tabular}{|c|c|c|c|c|c|c|c|c|}
\hline & & & & & & \multicolumn{3}{|c|}{ Fitted Distributions } \\
\hline Distribution & PEI & Probability & $15 \%$ & Mode & $85 \%$ & Min & Likely & $\operatorname{Max}$ \\
\hline Triangular Low Left & Mode & $1.0(75 \%)$ & 0.695 & 0.878 & 1.041 & 0.482 & 0.878 & 1.247 \\
\hline Triangular Low & Mode & $1.0(50 \%)$ & 0.834 & 1 & 1.166 & 0.633 & 1.000 & 1.367 \\
\hline Triangular Low Right & Mode & $1.0(25 \%)$ & 0.959 & 1.122 & 1.305 & 0.753 & 1.122 & 1.518 \\
\hline Triangular Medium Left & Mode & $1.0(75 \%)$ & 0.492 & 0.796 & 1.069 & 0.137 & 0.796 & 1.412 \\
\hline Triangular Medium & Mode & $1.0(50 \%)$ & 0.723 & 1 & 1.277 & 0.388 & 1.000 & 1.612 \\
\hline Triangular Medium Right & Mode & $1.0(25 \%)$ & 0.931 & 1.204 & 1.508 & 0.588 & 1.204 & 1.863 \\
\hline Triangular High Left & Mode & $1.0(75 \%)$ & 0.347 & 0.754 & 1.103 & 0.000 & 0.754 & 1.550 \\
\hline Triangular High & Mode & $1.0(50 \%)$ & 0.612 & 1 & 1.388 & 0.142 & 1.000 & 1.858 \\
\hline Triangular High Right & Mode & $1.0(25 \%)$ & 0.903 & 1.236 & 1.711 & 0.442 & 1.236 & 2.225 \\
\hline Triangular EHigh Left & Mode & $1.0(75 \%)$ & 0.3 & 0.745 & 1.15 & 0.000 & 0.745 & 1.657 \\
\hline Triangular EHigh & Mode & $1.0(50 \%)$ & 0.509 & 1.004 & 1.5 & 0.000 & 1.004 & 2.100 \\
\hline Triangular EHigh Right & Mode & $1.0(25 \%)$ & 0.876 & 1.367 & 1.914 & 0.258 & 1.367 & 2.553 \\
\hline
\end{tabular}

Figure 13. Sample Distributional Spread per the U.S. Air Force Cost Analysis Handbook

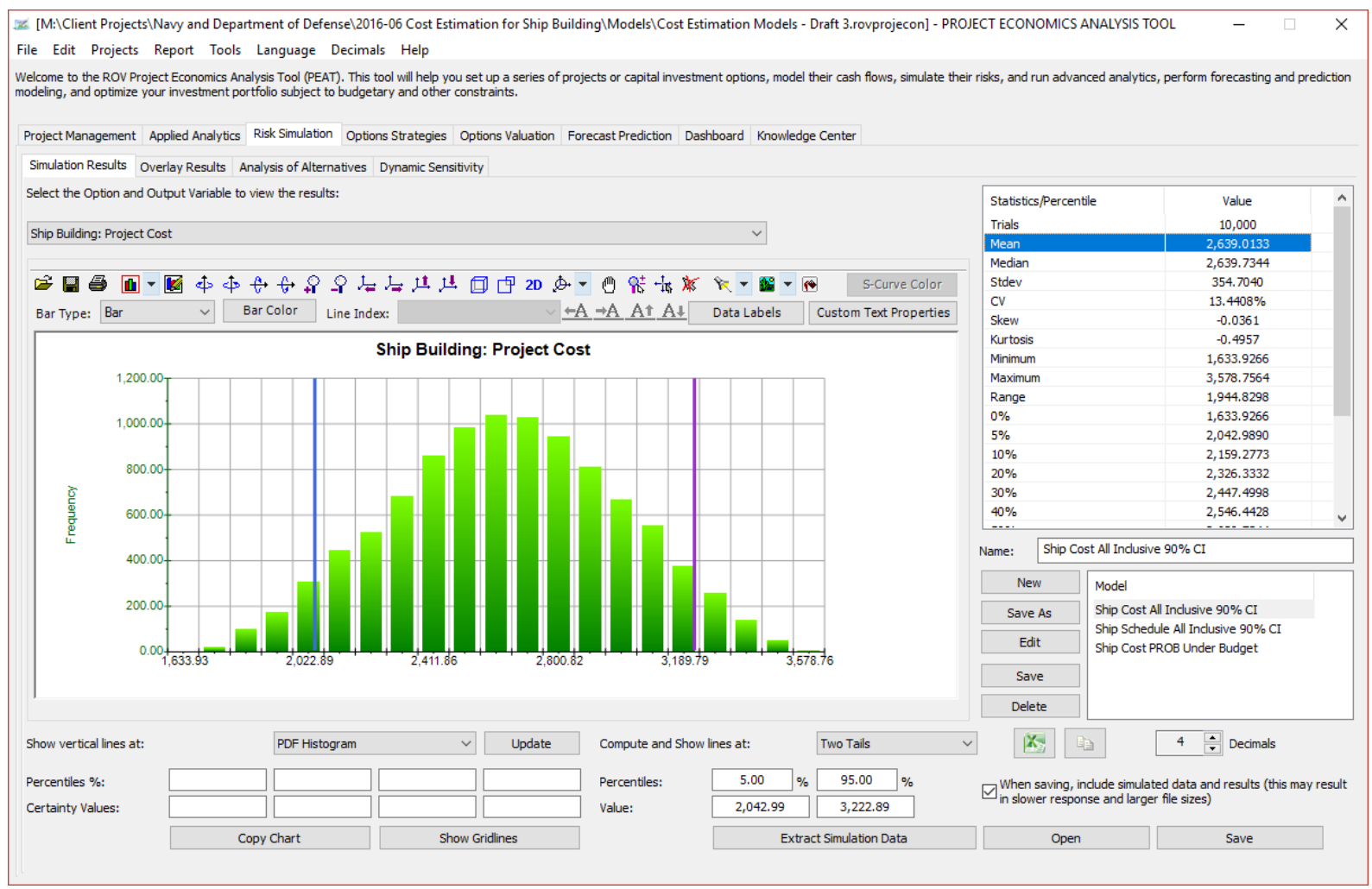

Figure 14. Simulation Results on Shipbuilding Cost (90\% Confidence Interval) 


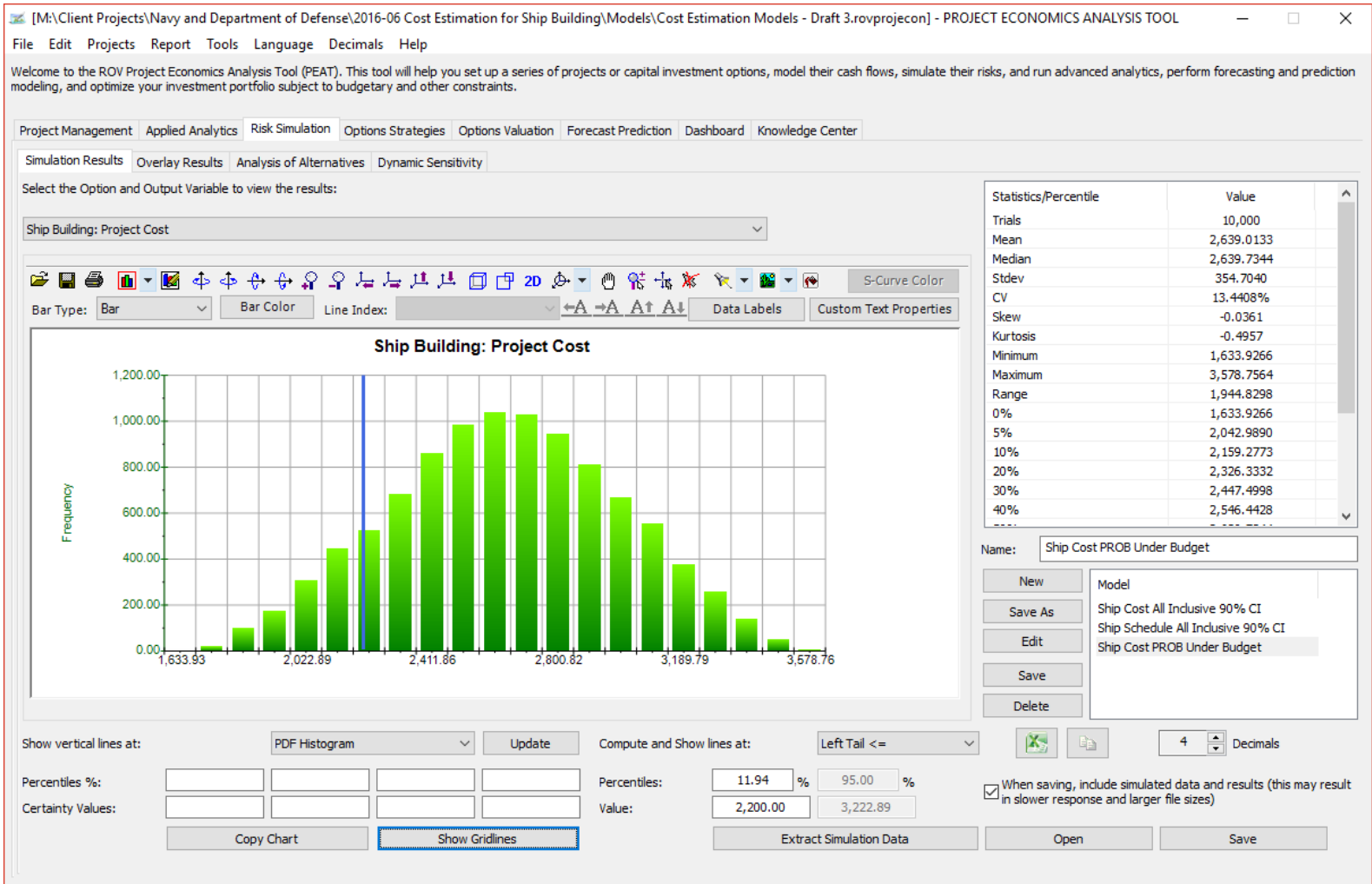

Figure 15. Probability of Cost Exceeding Budget

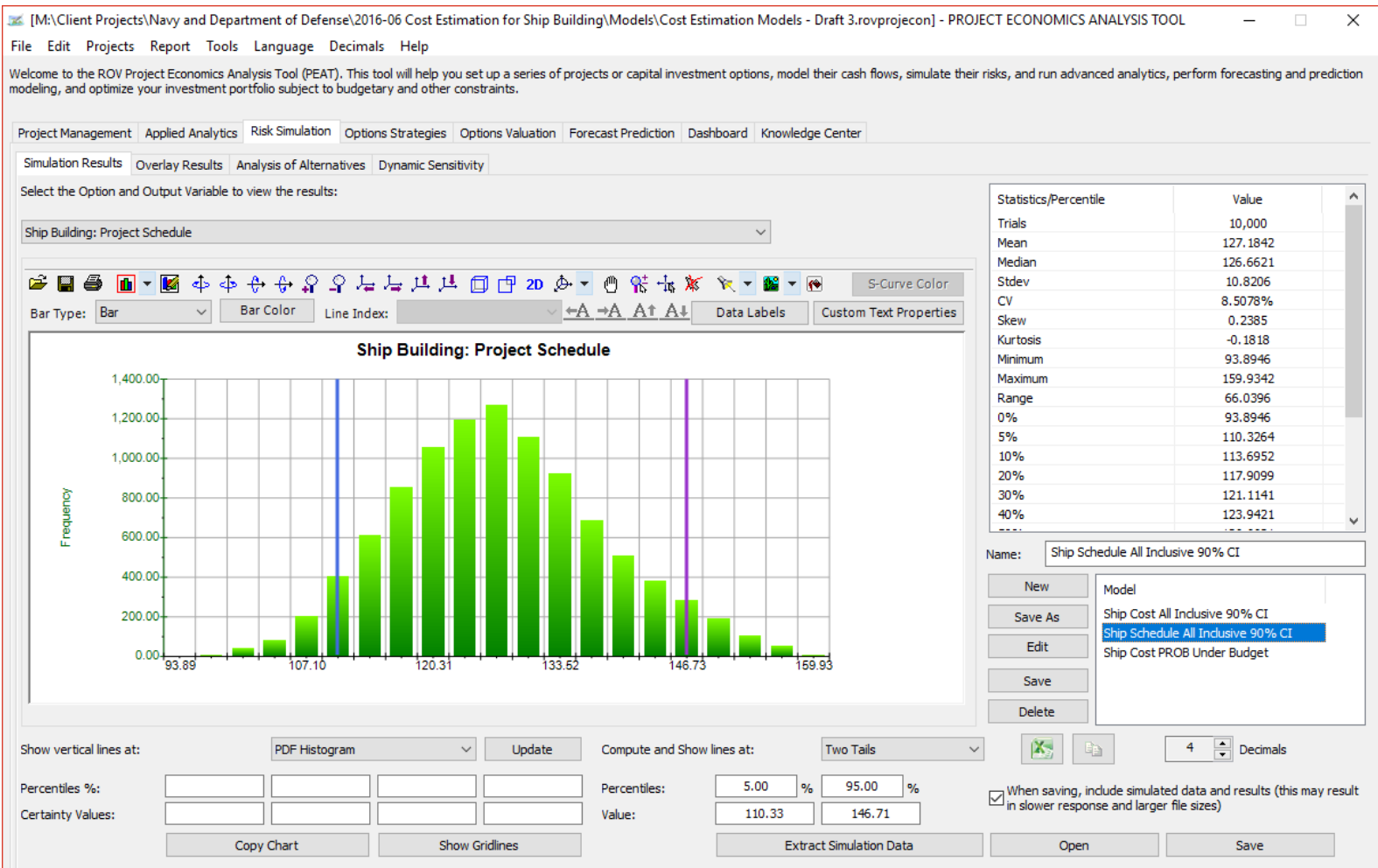

Figure 16. Schedule Risk (90\% Confidence Interval) 


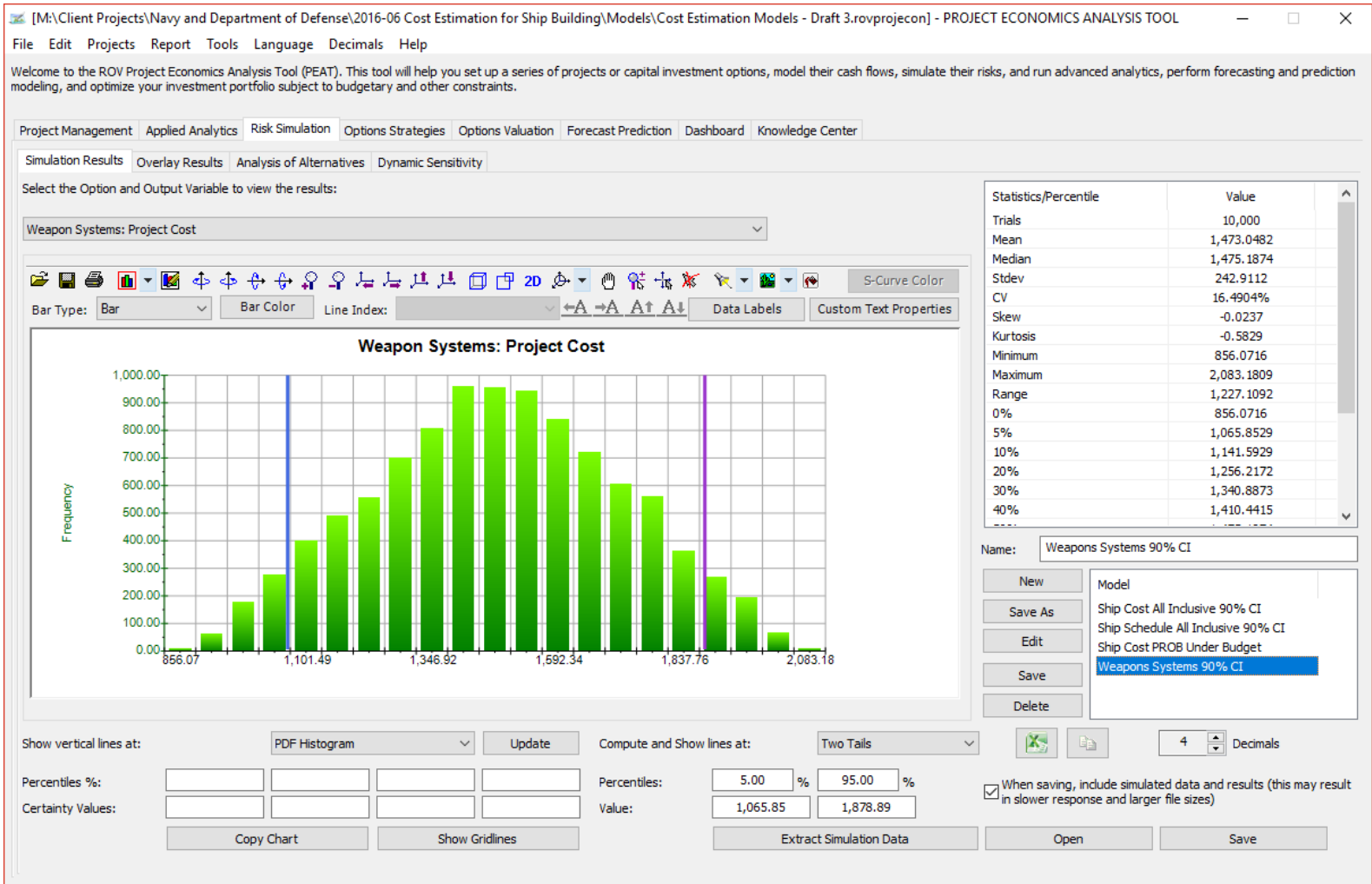

Figure 17. Cost of Weapons Systems (90\% Confidence Interval)

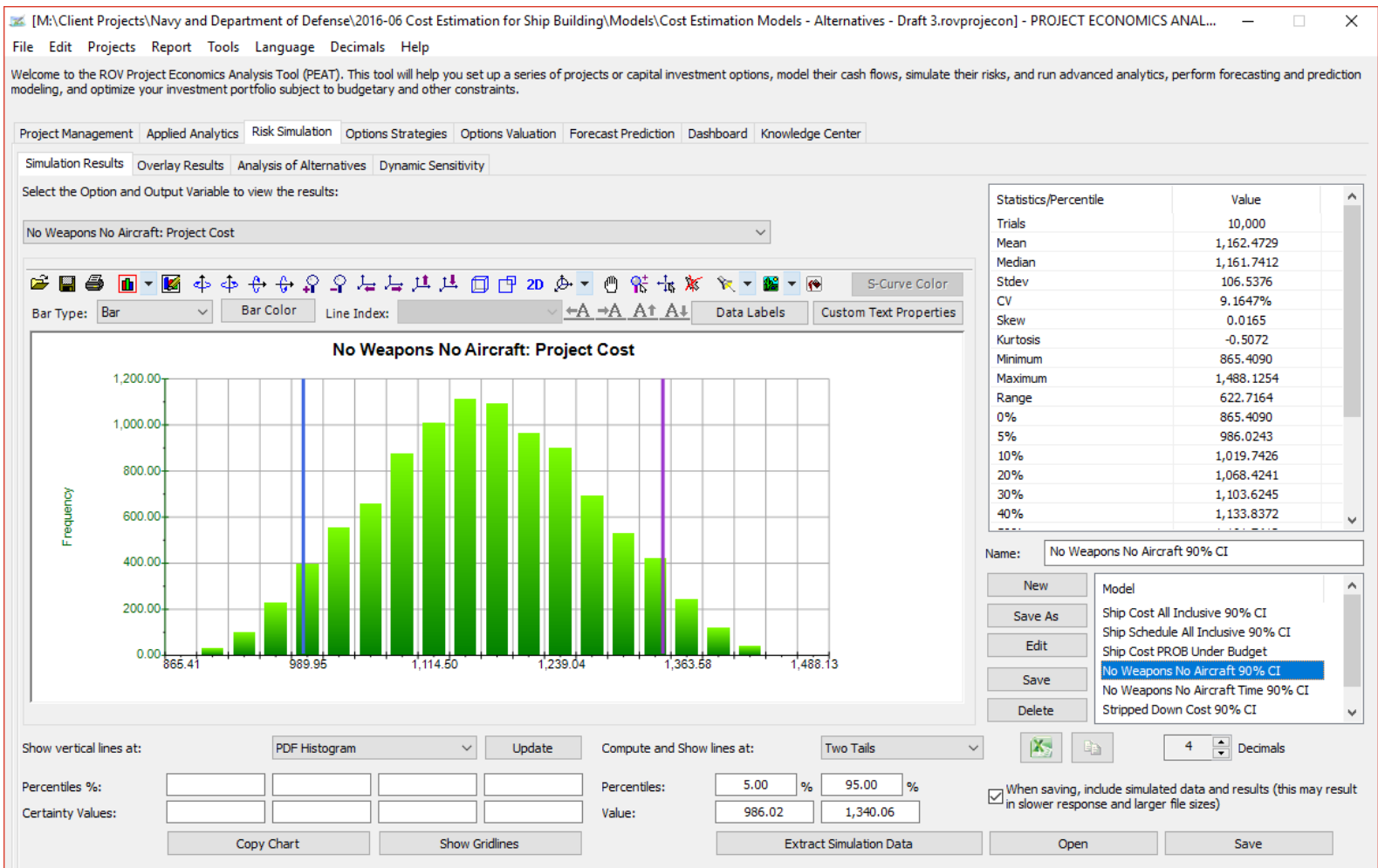

Figure 18. Simulated Cost of No Weapons and No Aircraft 


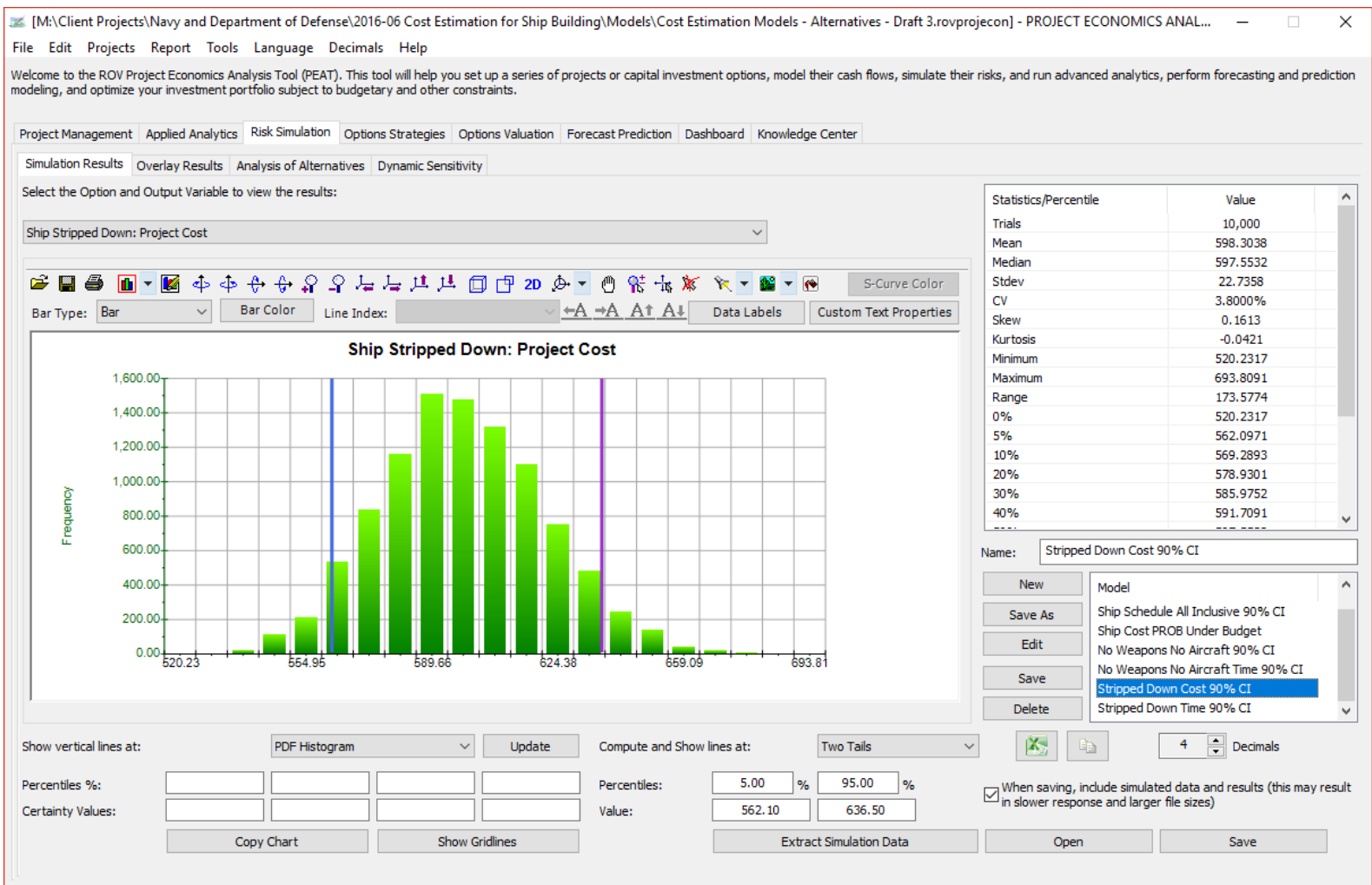

Figure 19. Simulated Cost of Stripped-Down Ship Build

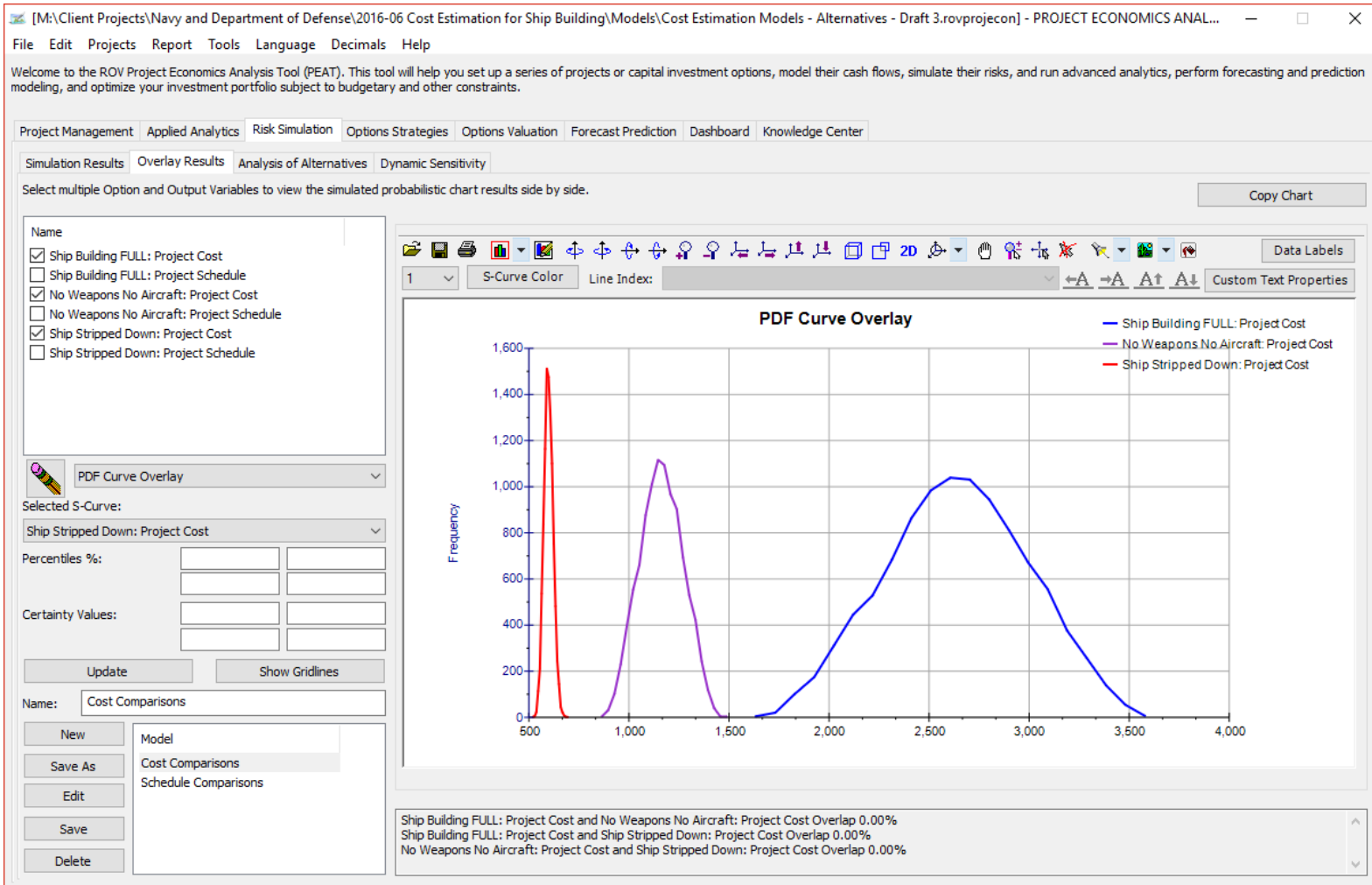

Figure 20. Comparative Analysis of Ship Configurations 


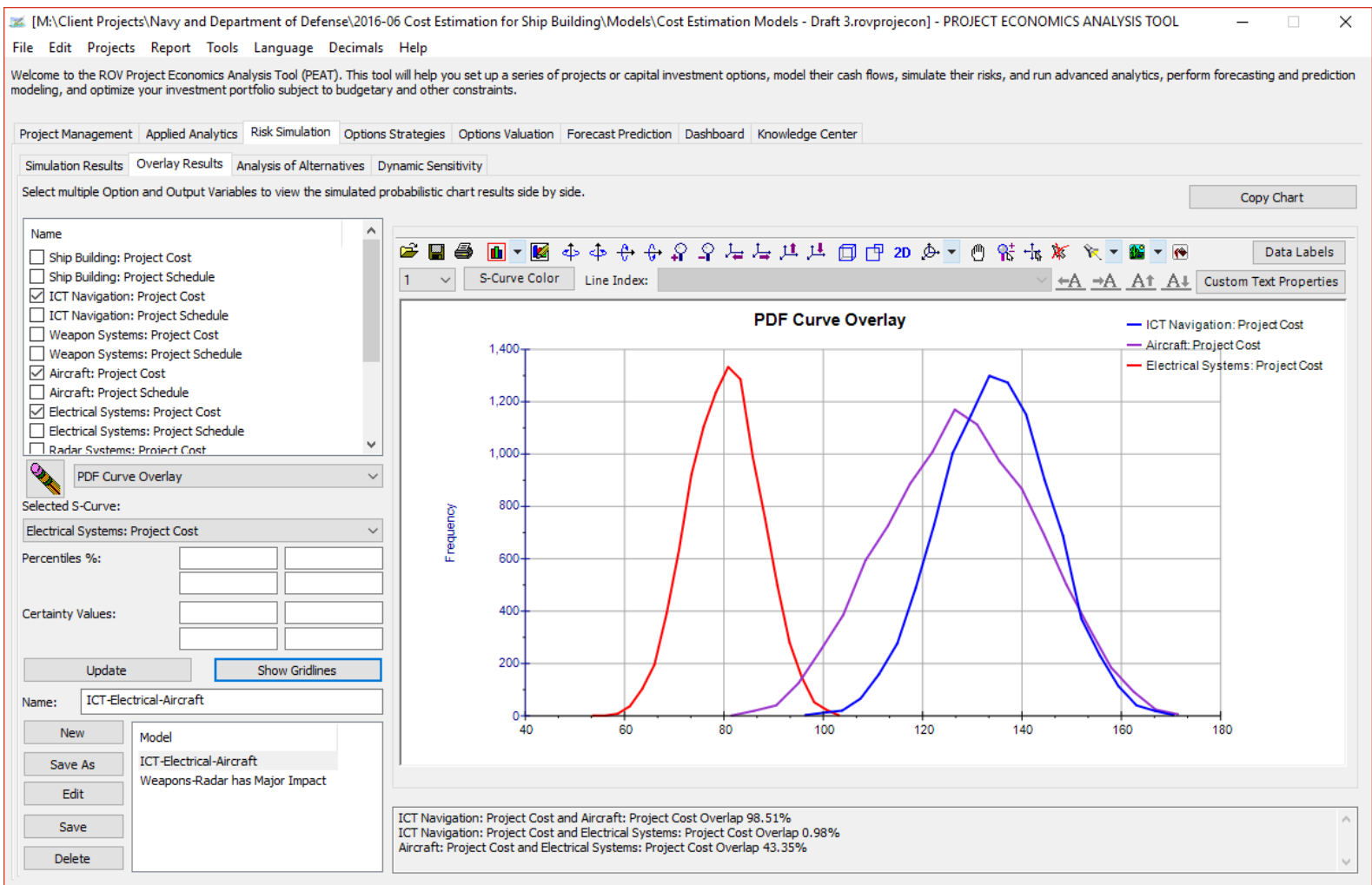

Figure 21. Overlay of Simulated Probability Distributions (Subsystems)

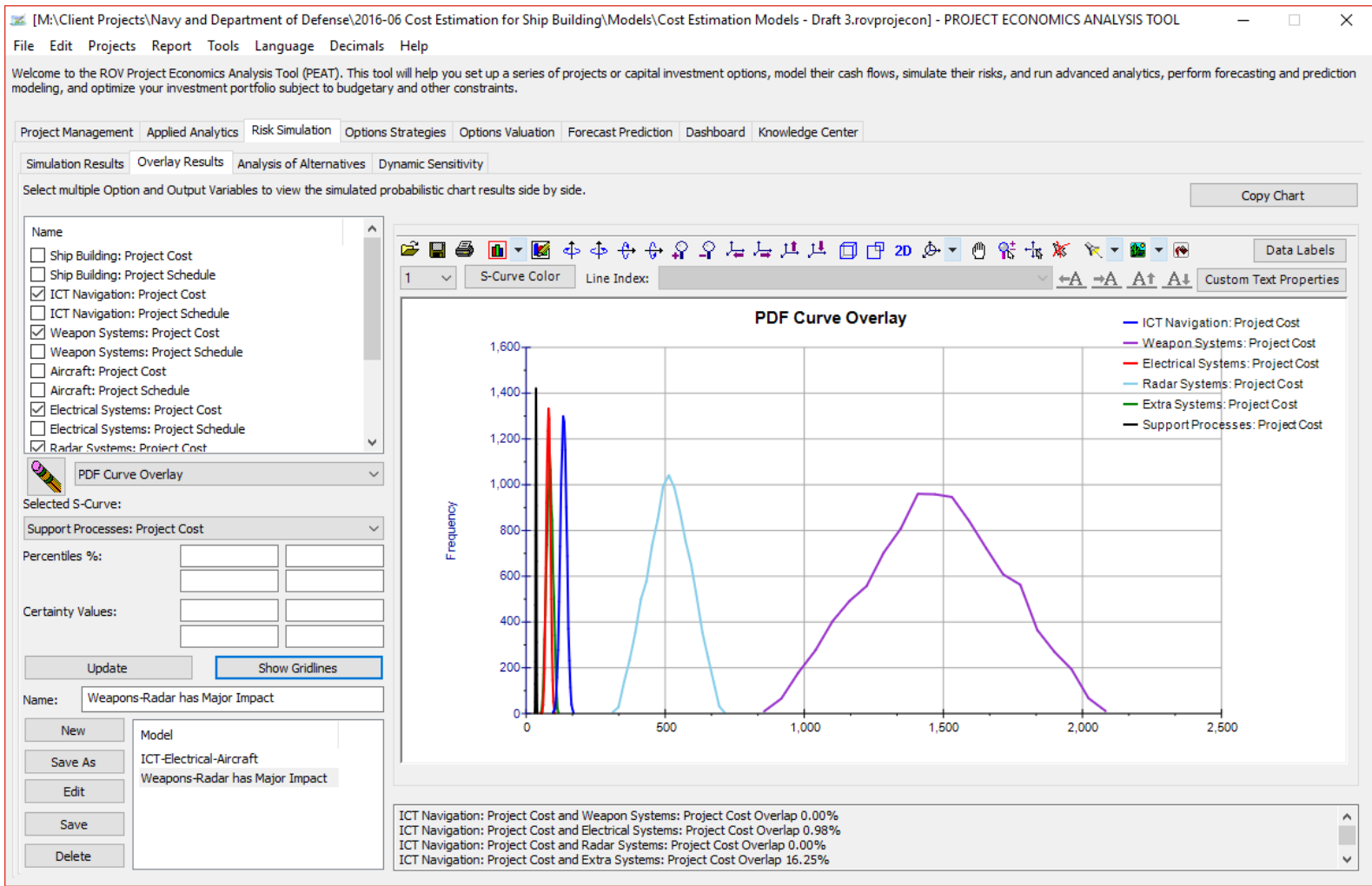

Figure 22. Overlay of Simulated Probability Distributions (All Subsystems) 


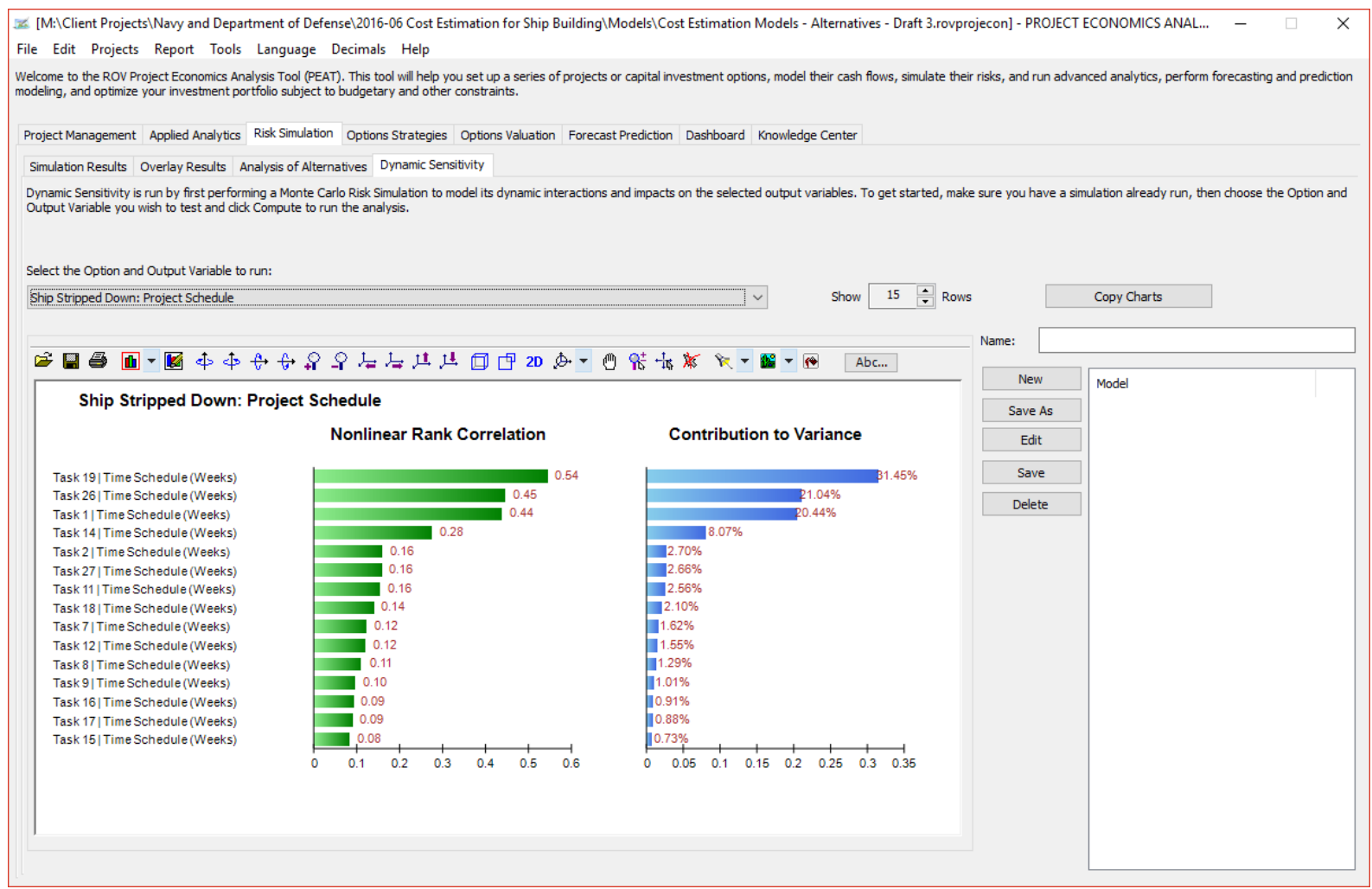

Figure 23. Dynamic Sensitivities of Stripped-Down Ship Build

\subsection{Parametric Cost Models with Historical Data}

A complementary approach to generate additional input cost assumptions includes the use of parametric modeling. To run parametric models, historical data is first required. Figure 24 shows an example dataset obtained via various defense agencies' publicly available information. The dataset shows various ship types, the unit costs (in millions), displacement in tons, speed, length, crew size, and year the ships were delivered.

Parametric models were developed and tested using simple multiple regression analysis, nonlinear regression, and econometric models. For instance, the following shows a simple linear parametric regression model and its results, where the functional form tested was:

$$
\begin{gathered}
y=\beta_{0}+\beta_{1} X_{1}+\beta_{2} X_{2}+\beta_{3} X_{3}+\beta_{4} X_{4} \\
\text { Cost }=-11837-0.10 \text { Tons }+80.44 \text { Speed } \\
+55.56 \text { Length }+6.09 \text { Crew }
\end{gathered}
$$

Although the model looks good, with statistically significant $p$-values (e.g., 0.0097) that are lower than the standard 0.05 or 0.10 significance cutoffs and coefficients of determination (R-squared) that are relatively high at $82.60 \%$, the model is flawed. For instance, the coefficient for displacement is negative, which defies conventional logic, where typically the heavier the ship, the higher the cost. This means the model's specification is incorrect and another model is required. Figure 25 shows a mixed nonlinear parametric model with the following specification:

$$
\begin{gathered}
y=\beta_{0}+\beta_{1} \ln \left(X_{1}\right)+\beta_{2} \ln \left(X_{2}\right)+\beta_{3} X_{3}+\beta_{4} X_{4} \\
\text { Cost }=-40271+3351 \ln (\text { Tons })+3952 \ln (\text { Speed }) \\
-26.37 \text { Length }-2.18 \text { Crew }
\end{gathered}
$$

This model makes slightly more sense in that tonnage and speed have a positive relationship to cost and their effects are nonlinear. However, some of the other independent variables such as crew and length still show negative effects, albeit all modeled variables have the statistical significance of low $p$-values and a higher adjusted R-squared coefficient. 


\begin{tabular}{|c|c|c|c|c|c|c|c|c|}
\hline Navy Ship & $\begin{array}{l}\text { Unit cost } \\
\text { (\$M) }\end{array}$ & $\begin{array}{l}\text { Displacement } \\
\text { (Tons) }\end{array}$ & $\begin{array}{l}\text { Speed } \\
\text { (КMH) }\end{array}$ & Length (M) & Crew & Year & Value & $\mathbf{Q}$ \\
\hline 1 DDG 51 & 2133 & 9648 & 56 & 155.3 & 276 & 2012 & 2,133 & 1 \\
\hline 2 DDG 51 & 1553 & 9648 & 56 & 155.3 & 276 & 2012 & 3,106 & 2 \\
\hline 3 DDG 51 & 1884 & 9648 & 56 & 155.3 & 276 & 2012 & 1,884 & 1 \\
\hline 4 DDG 51 & 1423 & 9648 & 56 & 155.3 & 276 & 2013 & 4,269 & 3 \\
\hline 5 DDG 51 & 2372 & 9648 & 56 & 155.3 & 276 & 2014 & 2372 & 1 \\
\hline 6 DDG 51 & 1615 & 9648 & 56 & 155.3 & 276 & 2015 & 1,615 & 1 \\
\hline 7 DDG 51 & 1330.5 & 9648 & 56 & 155.3 & 276 & 2016 & 2,661 & 2 \\
\hline 8 DDG 1000 & 3554 & 15730 & 56 & 185.9 & 148 & 2007 & 3554 & 1 \\
\hline 9 DDG 1000 & 3010 & 15730 & 56 & 185.9 & 148 & 2008 & 3010 & 1 \\
\hline 10 Joint High Speed Vessel (JHSV) & 185 & 2397 & 80 & 103 & 41 & 2010 & 185 & 1 \\
\hline 11 Joint High Speed Vessel (JHSV) & 184 & 2397 & 80 & 103 & 41 & 2011 & 184 & 1 \\
\hline 12 Joint High Speed Vessel (JHSV) & 376 & 2397 & 80 & 103 & 41 & 2012 & 376 & 1 \\
\hline 13 Joint High Speed Vessel (JHSV) & 207 & 2397 & 80 & 103 & 41 & 2013 & 207 & 1 \\
\hline 14 LHA 6 America & 3204 & 45695 & 37 & 114.91 & 1,687 & 2007 & 3,204 & 1 \\
\hline 15 LHA 6 America & 3213 & 45695 & 37 & 114.91 & 1,687 & 2011 & 3,213 & 1 \\
\hline 16 Littoral Combat Ship & 1077 & 3292 & 87 & 115.3 & 45 & 2010 & 1,077 & 1 \\
\hline 17 Littoral Combat Ship & 1147 & 3293 & 87 & 115.3 & 45 & 2011 & 1,147 & 1 \\
\hline 18 Littoral Combat Ship & 1858 & 3294 & 87 & 115.3 & 45 & 2012 & 1,858 & 1 \\
\hline 19 Littoral Combat Ship & 1821 & 3295 & 87 & 115.3 & 45 & 2013 & 1,821 & 1 \\
\hline 20 LPD 17 San Antonio Class & 1903 & 25300 & 39 & 208.5 & 360 & 2009 & 1,903 & 1 \\
\hline 21 LPD 17 San Antonio Class & 2088 & 25300 & 39 & 208.5 & 360 & 2012 & 2,088 & 1 \\
\hline 22 USS Ticonderoga (CG 47) & 1000 & 9754 & 56 & 173 & 30 & 2008 & 1,000 & 1 \\
\hline 23 DD-21 Zumwalt & 2700 & 16000 & 56 & 170 & 150 & 1996 & 2,700 & 1 \\
\hline 24 Nimitz Class Aircraft Carrier (CVN 68) & 4045 & 99800 & 56 & 332.8 & 558 & 2009 & 4,045 & 1 \\
\hline 25 Nimitz Class Aircraft Carrier (CVN 68) & 3421.3 & 99800 & 56 & 332.8 & 558 & 2011 & 3,421 & 1 \\
\hline 26 Nimitz Class Aircraft Carrier (CVN 68) & 4568.8 & 99800 & 56 & 332.8 & 558 & 2012 & 4,569 & 1 \\
\hline 27 Nimitz Class Aircraft Carrier (CVN 68) & 4738.2 & 99800 & 56 & 332.8 & 558 & 2016 & 4,738 & 1 \\
\hline
\end{tabular}

Figure 24. Sample Dataset for Parametric Modeling

The econometric-based parametric model shown in Figure 25 is the best model both in significance as well as logic. For instance, there are polynomial functions and first order versus second order interactions of the independent variables. Specifically, the functional form producing the best-fitting mixed nonlinear parametric cost model is:

$$
\begin{gathered}
\mathrm{y}=\beta_{0}+\beta_{1} X_{1}+\beta_{2} X_{3}+\beta_{3} X_{4}+\beta_{4} \ln \left(X_{1}\right)+\beta_{5} \ln \left(X_{2}\right)+\beta_{6} \ln \left(X_{3}\right) \\
\text { Cost }=86373-0.37 \text { Tons }+302.18 \text { Length }+4.39 \text { Crew }+7108.91 \ln (\text { Tons })+9778.02 \ln (\text { Speed }) \\
-46327.8 \ln (\text { Length })
\end{gathered}
$$

Clearly these are only illustrations based on sample publicly available data. Nonetheless, the approach is similar with actual data. The only difference would be to use datasets that pertain to the ship that is being modeled to prevent out-of-sample biases. Additional independent variables will need to be collected, and various econometric tests will need to be performed. 


\section{Basic Econometrics Analysis Report}

\begin{tabular}{lr}
\hline Regression Statistics & \\
\hline \hline R-Squared (Coefficient of Determination) & 0.9027 \\
Adjusted R-Squared & 0.8850 \\
Multiple R (Multiple Correlation Coefficient) & 0.9501 \\
Standard Error of the Estimates (SEy) & 437.4818 \\
Number of Observations & 27 \\
\hline
\end{tabular}

The R-Squared or Coefficient of Determination indicates that 0.90 of the variation in the dependent variable can be explained and accounted for by the independent variables in this regression analysis. However, in a multiple regression, the Adjusted R-Squared takes into account the existence of additional independent variables or regressors and adjusts this R-Squared value to a more accurate view of the regression's explanatory power. Hence, only 0.89 of the variation in the dependent variable can be explained by the regressors.

The Multiple Correlation Coefficient (Multiple R) measures the correlation between the actual dependent variable $(\mathrm{Y})$ and the estimated or fitted $(\mathrm{Y})$ based on the regression equation. This is also the square root of the Coefficient of Determination (R-Squared).

The Standard Error of the Estimates (SEy) describes the dispersion of data points above and below the regression line or plane. This value is used as part of the calculation to obtain the confidence interval of the estimates later.

\begin{tabular}{lrrrrr}
\hline Regression Results & \multicolumn{5}{l}{} \\
\hline \hline & Intercept & LN(VAR2) & LN(VAR3) & VAR4 & VAR5 \\
Coefficients & -40271.8660 & 3351.7927 & 3952.3622 & -26.3671 & -2.1820 \\
Standard Error & 7260.7364 & 596.1151 & 828.0072 & 6.9614 & 0.6903 \\
t-Statistic & -5.5465 & 5.6227 & 4.7733 & -3.7876 & -3.1609 \\
p-Value & 0.0000 & 0.0000 & 0.0001 & 0.0010 & 0.0045 \\
Lower 5\% & -55329.7116 & 2115.5257 & 2235.1804 & -40.8042 & -3.6136 \\
Upper 95\% & -25214.0205 & 4588.0597 & 5669.5439 & -11.9300 & -0.7504
\end{tabular}

Degrees of Freedom

Degrees of Freedom for Regression

Degrees of Freedom for Residual

Total Degrees of Freedom
Hypothesis Test

Critical t-Statistic ( $99 \%$ confidence with df of 22) 2.8188

Critical t-Statistic ( $95 \%$ confidence with df of 22)

Critical t-Statistic ( $90 \%$ confidence with df of 22)

Figure 25. Parametric Model with Nonlinear Regression

\subsection{Parametric Probability Distribution and Curve Fitting}

Another powerful cost modeling approach is distributional fitting; that is, how does an analyst or engineer determine which distribution to use for a particular task's input cost or schedule variable? What are the relevant distributional parameters? If no historical data exist, we can make assumptions about the variables in question using the qualitative Delphi method, where a group of subject matter experts are tasked with estimating the behavior of each variable. Then, these values can be used as the variable's input parameters (e.g., uniform distribution with extreme values between 0.5 and 1.2). When testing is not possible (e.g., a new or novel weapon subsystem), management can still make estimates of potential outcomes and provide the best-case, most-likely case, and worst-case scenarios, whereupon a triangular or custom distribution can be created.

However, if reliable historical data are available, distributional fitting can be accomplished. Assuming that historical patterns hold, and that history tends to repeat itself, then historical data can be used to find the best-fitting distribution with their relevant parameters to better define the variables to be simulated. Figure 26 illustrates a distributional-fitting example of the costs shown previously (Figure 24).

The null hypothesis $\left(\mathrm{H}_{\mathrm{o}}\right)$ being tested is such that the fitted distribution is the same distribution as the population from which the sample data to be fitted came. Thus, if the computed $p$-value is lower than a critical alpha level (typically .10 or .05), the distribution is the wrong distribution. Conversely, the higher the $p$-value, the better the distribution fits the data. Roughly, you can think of $p$-value as a percentage explained; that is, if the $p$-value is 0.9849 (Figure 26), then setting a normal distribution with a mean of 1990 and a standard deviation of 1290 explains about $98.49 \%$ of the variation in the data, indicating an especially good fit. The results from the Risk Simulator software also rank all the selected distributions and how well they fit the data. The fitted distribution can now be set up to run a simulation. The results from the simulation (tens to hundreds of thousands of simulation trials can be run) can be interpreted accurately (Figure 27). 


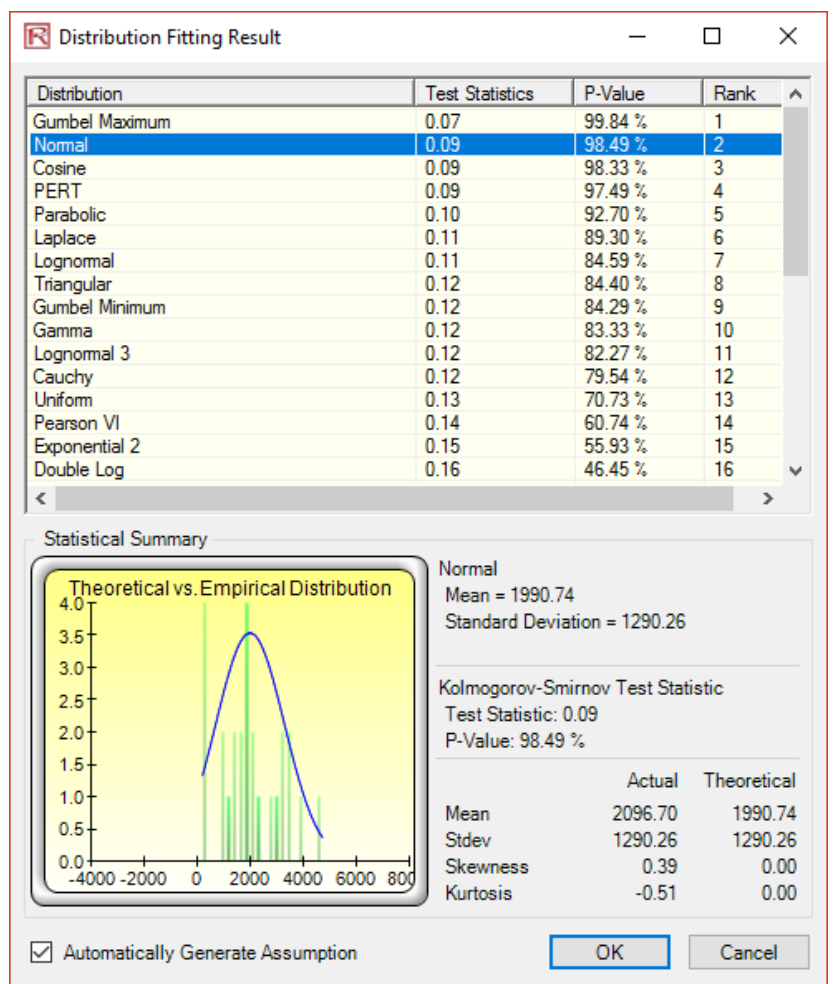

Figure 26. Parametric Monte Carlo Simulation Model Distributional Fitting

图 Parametric Simulated Cost - Risk Simulator Forecast

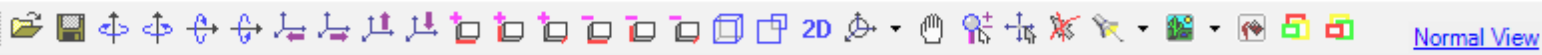

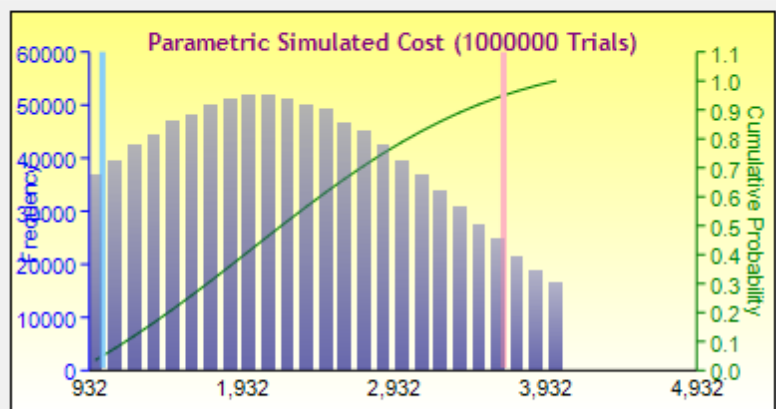

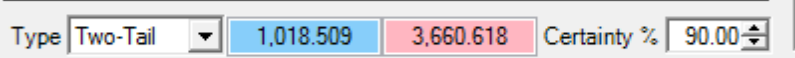

\begin{tabular}{|l|r|}
\hline Statistics & Result \\
\hline Number of Trials & 1000000 \\
\hline Mean & 2.248 .2892 \\
\hline Median & 2.197 .5294 \\
\hline Standard Deviation & 812.1175 \\
\hline Variance & 659.534 .7620 \\
Coefficient of Variation & 0.3612 \\
\hline Maximum & 3.999 .9804 \\
\hline Minimum & 850.0090 \\
\hline Range & 3.149 .9714 \\
Skewness & 0.2108 \\
\hline Kurtosis & -0.9211 \\
\hline $25 \%$ Percentile & 1.582 .8012 \\
\hline $75 \%$ Percentile & 2.867 .6844 \\
Percentage Error Precision at 95\% Confidence & $0.0708 \%$ \\
\hline
\end{tabular}

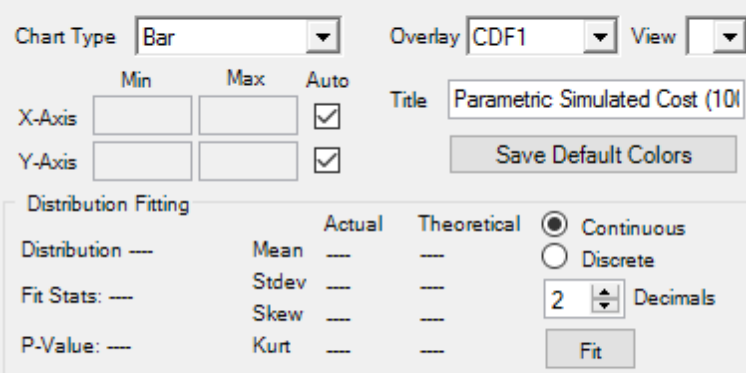

Histogram Resolution

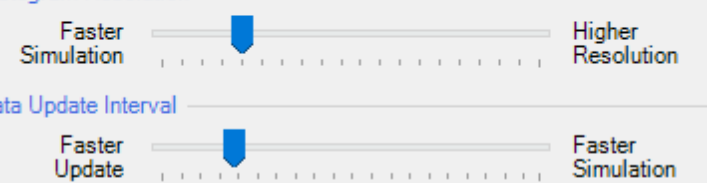

Data Filter
C) Show all data
Show only data between - Infinity and Infinity
Show only data within 64 standard deviation(s)

Statistic

Precision level used to calculate the error: $95 \div$

Show the following statistic(s) on the histogram:

$\square$ Mean $\square$ Median $\square$ 1st Quartile $\square$ 3rd Quartile

Show Decimals

Chart X-Axis $0 \div$ Confidence $3 \div$ Statistics $4 \div$

Display Control

\begin{tabular}{ll|l}
$\square$ Always Show Window On Top Close All Excel \\
\hline
\end{tabular}

$\square$ Semitransparent When Inactive Minimize All

Copy Chart

Figure 27. Parametric Simulated Cost Results 


\section{Conclusions and Next Step Recommendations}

Based on this preliminary analysis and review of the alternatives, we conclude that the risk-based cost and schedule simulations as well as parametric econometric models can be applied to modeling the cost of current and future U.S. Navy warships. It is evident in the analysis that any cost modeling must also include schedule risk because schedule delays can cause significant cost creep and budget overruns. Using the project process diagrams and task-based cost modeling coupled with Monte Carlo simulations to account for uncertainties in input assumptions and estimates and risks of overruns, a comprehensive methodology was developed.

We therefore recommend the following:

- Collect and use actual cost data and develop more accurate cost estimates going forward in order to better calibrate the inputs based on real-life conditions. (We can provide suggestions on how to generate a database and methods to capture said required data.)

- Use the Risk Simulator-based simulated probability distributions to determine how well the vendors are performing (e.g., running at $92 \%$ efficiency, etc.), thus creating a common set of agreed upon performance metrics for the organization.

- Use control charts (based on simulated results) to determine if processes and tasks are in-control or out-of-control over time.

- Identify critical success factors to start collecting cost and schedule data for more accurate estimates.

- Incorporate learning curves and synergies when more than one ship is on order and the unit cost per ship would be lower.

The next phase of this research will focus on collecting actual cost and schedule data from a specific ship with subject matter experts' inputs to obtain the qualitative values. The resulting simulations will provide an alternative to the existing cost and schedule forecasting models that can be compared for accuracy over the course of the ship build. If complete archival cost and schedule data are available for a specific ship build along with the forecasted costs and schedule, this data can be applied to the ship cost model forecasting approaches suggested by the current study for purposes of comparison to the existing models that were used during the ship build.

\section{Appendix: Most Common Forecast and Predictive Modeling Techniques}

- ARIMA \{ XE "ARIMA (see alsol: auto-ARIMAl; autoregressive integrated moving averagel; autoregressive process)" \}. Autoregressive integrated moving average \{ XE "Autoregressive integrated moving average (see alsol: ARIMA)” \} \{ XE "Moving average" \} (ARIMA, also known as BoxJenkins ARIMA) is an advanced econometric modeling technique. ARIMA looks at historical\{ XE "Historical" \} time-series \{ XE "Time-series" \} data $\{\mathrm{XE}$ ““ $\}$ and performs back-fitting $\{\mathrm{XE}$ "Fitting” \} optimization \{ XE "Optimization" \} routines to account for historical autocorrelation (the relationship of a variable's values over time, that is, how a variable's data is related to itself over time). It accounts for the stability of the data to correct for the nonstationary characteristics of the data, and it learns over time by correcting its forecasting errors. Think of ARIMA as an advanced multiple regression model, where time-series variables are modeled and predicted using its historical data as well as other time-series explanatory variables. Advanced knowledge in econometrics is typically required to build good predictive models using this approach. Suitable for time-series and mixed-panel data (not applicable for cross-sectional data).

- Auto-ARIMA\{ XE "ARIMA (see alsol: auto-ARIMAl; autoregressive integrated moving averagel; autoregressive process)" $\}$. The Auto-ARIMA\{ XE "Auto-ARIMA (see alsol: ARIMAl; autoregressive integrated moving averagel; autoregressive process)" \} module automates some of the traditional ARIMA modeling by automatically testing multiple permutations of model\{XE ““ $\}$ specifications and returns \{XE “““ $\}$ the best-fitting \{ XE "Fitting” \} model. Running the Auto-ARIMA module is like running regular ARIMA forecasts; the differences being that the required $\mathrm{P}, \mathrm{D}, \mathrm{Q}$ inputs in ARIMA are no longer required and that different combinations of these inputs are automatically run and compared. Suitable for time-series $\{$ XE “Time-series" $\}$ and mixed-panel data $\{\mathrm{XE}$ ““ $\}$ (not applicable for cross-sectional data).

- Basic Econometrics \{ XE "Econometrics" \}. Econometrics refers to a branch of business analytics, modeling, and forecasting techniques for modeling the behavior or forecasting of certain business, economic, finance, physics, manufacturing, operations, and any other variables. Running Basic Econometrics models is similar to regular regression analysis except that the dependent and independent variable XE "Independent variable" \}s are allowed to be modified before a regression is run. Suitable for all types of data\{ XE ““ $\}$.

- Basic Auto Econometrics\{ XE "Econometrics"\}. This methodology is similar to basic econometrics, but thousands of linear\{ XE "Linear" \}, nonlinear\{ XE "Nonlinear" \}, interacting, lagged, and mixed variables are automatically run on your data\{ XE ““ $\}$ to determine the best-fitting \{ XE "Fitting" \} econometric model $\{X E$ “ “ $~\}$ that describes the behavior of the dependent variable\{ XE "Dependent 
variable” $\}$. It is useful for modeling the effects of the variables and for forecasting future outcomes, while not requiring the analyst to be an expert econometrician. Suitable for all types of data.

- Combinatorial Fuzzy Logic. Fuzzy sets deal with approximate rather than accurate binary logic. Fuzzy values are between 0 and 1 . This weighting schema is used in a combinatorial method to generate the optimized time-series\{ XE “Time-series” \} forecasts. Suitable for time-series only.

- Custom\{ XE “Custom” \} Distributions. Using Risk\{ $X E$ ““ $\}$ Simulator $\{X E$ ““ $\}\{X E$ “ “ $\}$, expert opinions can be collected, and a customized distribution can be generated. This forecasting technique comes in handy when the dataset is small, the Delphi method is used, or the goodness-of-fit\{ XE "Goodness-of-fit" \} is bad when applied to a distributional fitting \{ XE "Fitting" \} routine. Suitable for all types of data\{ XE ““ $\}$.

- GARCH \{ XE "GARCH" \}. The generalized autoregressive conditional heteroskedasticity (GARCH) model \{XE ““ $\}$ is used to model historical\{ XE "Historical” $\}$ and forecast\{ XE ““ $\}$ future volatility \{ XE "Volatility" \} levels of a marketable security (e.g., stock price \{ XE "Stock price" $\}$ s, commodity prices, oil prices, etc.). The dataset has to be a time series of raw price levels. GARCH will first convert the prices into relative returns \{ $\mathrm{XE}$ ““ $\}$ and then run an internal optimization \{ XE "Optimization" \} to fit the historical data $\{\mathrm{XE}$ ““” $\}$ to a mean $\{\mathrm{XE}$ ““، \} -reverting volatility term structure, while assuming that the volatility is heteroskedastic in nature (changes over time according to some econometric characteristics). Several variations of this methodology are available in Risk $\{\mathrm{XE}$ ““ $\}$ Simulator\{ XE ““ $\}$ XE ““ $\}$, including EGARCH\{ XE "EGARCH" \}, EGARCH-T\{ XE "EGARCH-T" \}, GARCH-M, GJR-GARCH\{ XE "GJR-GARCH" \}, GJR-GARCH-T \{ XE "GJR-GARCH-T" \} , IGARCH \{ XE "IGARCH" \}, and T-GARCH. Suitable for time-series \{ XE “Time-series” $\}$ data only. This technique can be used with cost data in the current ship costs context by forecasting ship cost volatility.

- J-Curve. The J-curve\{ XE "J-curve" $\}$ XE ““ $\}$, or exponential growth curve, is one where the growth of the next period depends on the current period's level and the increase is exponential. This phenomenon means that over time, the values will increase significantly, from one period to another. This model \{ $\mathrm{XE}$ ““ $\}$ is typically used in forecasting biological growth and chemical reactions over time. Suitable for time-series\{ XE “Time-series” \} data\{ XE ““ $\}$ only. It can be used in the current cost context by forecasting cost growth data.
- Markov Chains. A Markov chain exists when the probability of a future state depends on a previous state and when linked together forms a chain that reverts to a long-run steady-state level. This approach is typically used to forecast $\{\mathrm{XE}$ “' $\}$ the market share of two competitors. The required inputs are the starting probability of a customer in the first state returning to the same state in the next period, versus the probability of switching to a competitor's state in the next state. Suitable for time-series \{ XE “Time-series” \} data\{ XE ““ \} only.

- Maximum Likelihood on Logit\{ XE "Logit model” \}, Probit, and Tobit. Maximum likelihood estimation\{ XE "Maximum likelihood estimation, MLE" \} (MLE \{ XE "Maximum likelihood estimation, MLE” \}) is used to forecast $\{\mathrm{XE}$ “ “ $~\}$ the probability of something occurring given some independent variable\{ XE "Independent variable" $\}$ s. For instance, MLE is used to predict if a credit\{ XE "Credit" $\}$ line or debt will default $\{\mathrm{XE}$ “ “ $\}$ given the obligor's characteristics (30 years old, single, salary of $\$ 100,000$ per year, and total credit card debt of $\$ 10,000$ ), or the probability a patient will have lung cancer if the person is a male between the ages of 50 and 60 , smokes five packs of cigarettes per month or year, and so forth. In these circumstances, the dependent variable XE "Dependent variable" $\}$ is limited (i.e., limited to being binary 1 and 0 for default/die and no default/live, or limited to integer values such as $1,2,3$, etc.) and the desired outcome of the model $\{\mathrm{XE}$ ““ $\}$ is to predict the probability of an event occurring. Traditional \{ XE "Traditional" \} regression analysis will not work in these situations (the predicted probability is usually less than zero or greater than one, and many of the required regression assumptions are violated, such as independence and normality of the errors, and the errors will be fairly large). Suitable for cross-sectional data $\{\mathrm{XE}$ “ “' $\}$ only. Multivariate Regression \{ XE "Regression" \}. Multivariate regression\{ XE "Regression" \} is used to model $\{\mathrm{XE}$ “““ $\}$ the relationship structure and characteristics of a certain dependent variable\{ XE "Dependent variable" $\}$ as it depends on other independent exogenous variables. Using the modeled relationship, we can forecast $\{\mathrm{XE}$ “" $\}$ the future values of the dependent variable. The accuracy and goodness-of-fit \{ XE “Goodness-of-fit” \} for this model can also be determined. Linear and nonlinear \{ XE "Nonlinear" \} models can be fitted in the multiple regression analysis. Suitable for all types of data\{ XE ““'\}.

- Neural Network. This method creates artificial neural network \{ XE "Neural network" \} s, nodes, and neurons inside software algorithms for the purposes of forecasting time-series \{ XE “Time-series" \} 
variables using pattern recognition. Suitable for time-series data $X \mathrm{XE}$ ““ $\}$ only.

- Nonlinear Extrapolation\{XE “Extrapolation” \}. In this methodology, the underlying structure of the data $\{\mathrm{XE}$ “ “ $\}$ to be forecasted is assumed to be nonlinear\{ XE "Nonlinear" \} over time. For instance, a dataset such as $1,4,9,16,25$ is considered to be nonlinear (these data points are from a squared function). Suitable for time-series\{ XE "Time-series" \} data only.

- S-Curves. The S-curve $\{$ XE "S-curve" $\}$ XE ““ $\}$, or logistic growth curve, starts off like a J-curve\{ XE "J-curve" \}, with exponential growth rates. Over time, the environment becomes saturated (e.g., market saturation, competition, overcrowding), the growth slows, and the forecast\{XE ““ $\}$ value eventually ends up at a saturation or maximum level. The S-curve model $\{\mathrm{XE}$ ““ $\}$ is typically used in forecasting market share or sales growth of a new product from market introduction until maturity and decline, population dynamics, and other naturally occurring phenomenon. Suitable for time-series $\{\mathrm{XE}$ “Time-series” \} data\{ XE “““ $\}$ only.

- Spline\{ XE "Spline curves, cubic spline” \} Curves. Sometimes there are missing values in a time-series \{ XE “Time-series" \} dataset. For instance, interest rates for years 1 to 3 may exist, followed by years 5 to 8 , and then year 10. Spline curves\{ XE "Spline curves, cubic spline" \} can be used to interpolate the missing years' interest rate values based on the data $\mathrm{XE}$ “ ““ $\}$ that exist. Spline curves can also be used to forecast\{ XE ““ $\}$ or extrapolate values of future time periods beyond the time period of available data. The data can be linear \{ XE "Linear" $\}$ or nonlinear $\{\mathrm{XE}$ "Nonlinear" \}. Suitable for time-series data only.

- Stochastic\{XE "Stochastic, stochastic process (see alsol: Brownian motionl; random walks)" \} Process Forecasting \{XE "Forecasting" \}. Sometimes variables are stochastic $\{\mathrm{XE}$ "Stochastic, stochastic process (see alsol: Brownian motion〉; random walks)" \} and cannot be readily predicted using traditional means. Nonetheless, most financial \{ XE ““ $\}$, economic, and naturally occurring phenomena (e.g., motion of molecules through the air) follow a known mathematical law or relationship. Although the resulting values are uncertain, the underlying mathematical structure is known and can be simulated using Monte Carlo\{ XE "Monte Carlo, Monte Carlo simulation” $\}$ risk simulation \{ XE ““ $\}$. The processes supported in Risk\{XE ““ $\}$ Simulator \{ $\mathrm{XE}$ ““ $\}\{\mathrm{XE}$ ““ $\}$ include Brownian motion $\{\mathrm{XE}$ "Brownian motion (see alsol: random walks〉; stochasticl; stochastic process)” \} random walk\{ XE

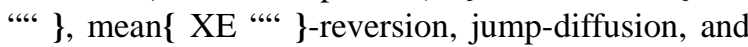
mixed processes, useful for forecasting nonstationary time-series\{ XE “Time-series” $\}$ variables. Suitable for time-series data XE ““” $\}$ only.

- Time-Series Analysis and Decomposition \{ XE "Decomposition" $\}$. In well-behaved time-series \{ $\mathrm{XE}$ “Time-series” $\}$ data $\{\mathrm{XE}$ ““ $\}$ (typical examples include sales revenues and cost structures of large corporations), the values tend to have up to three elements: a base value, trend, and seasonality \{ XE "Seasonal, seasonality" \}. Time-series analysis\{ $\mathrm{XE}$ "Time-series forecast, time-series analysis" \} uses these historical \{ XE "Historical” \} data and decomposes them into these three elements and recomposes them into future forecasts. In other words, this forecasting method, like some of the others described, first performs a back-fitting\{ XE "Fitting" \} (backcast) of historical data before it provides estimates of future values (forecasts). Suitable for time-series data only.

- Trendlines. This method fits various curves such as linear\{ XE "Linear" \}, nonlinear\{ XE "Nonlinear" \}, moving average $\{\mathrm{XE}$ "Moving average" $\}$, exponential, logarithmic, polynomial, and power functions on existing historical XE "Historical" \} data $\{\mathrm{XE}$ ““ $\}$. Suitable for time-series $\{\mathrm{XE}$ "Time-series" $\}$ data only.

\section{REFERENCES}

[1] Brown, A., \& Neu, W. (2008). Naval surface ship design optimization for affordability: Phase I.

[2] Congressional Budget Office. (2015, October). An analysis of the Navy's Fiscal Year 2016 shipbuilding plan. Retrieved fromhttps://www.cbo.gov/sites/default/files/114th-congres s-2015-2016/reports/50926-Shipbuilding.pdf

[3] Cost Assessment Data Enterprise (CADE). (2014). Joint Agency Cost Schedule Risk and Uncertainty Handbook (CSRUH). Retrieved from http://cade.osd.mil/cade/CSRU H.aspx

[4] Deegan, C. (2005). NAVSEA Cost Estimation Handbook. Washington, DC: Naval Sea Systems Command.

[5] Deschamps, L., \& Greenwell, C. (n.d.). Integrating cost estimating with the ship design process.

[6] Kaluzny, B. L., Barbici, S., Berg, G., Chiomento, R., Derpanis, D., Jonsson, U., Ramaroson, F. (2011). An application of data mining algorithms for shipbuilding cost estimation. Journal of Cost Analysis and Parametrics, 4(1), 2-30. doi:10.1080/1941658X.2011.585336

[7] Lee, U. (2014). Improving the parametric method of cost estimating relationships of naval ships (Master's thesis). Cambridge, MA: Massachusetts Institute of Technology.

[8] Miroyannis, A. (2006). Estimation of ship construction costs (Master’s thesis). Cambridge, MA: Massachusetts Institute of Technology. 
[9] Mislick, G. K., \& Nussbaum, D. A. (2015). Cost Estimation: Methods and Tools. Hoboken, NJ: Wiley.

[10] Moore, G. W., \& White, E. D. (2005). A regression approach for estimating procurement cost. Journal of Public Procurement, 5(2), 187-209.

[11] Mulligan, R. F. (2008, September 1). A simple model for estimating newbuilding costs. Maritime Economics \& Logistics, 10(3), 310-321.

[12] Mun, Johnathan. Modeling Risk: Applying Monte Carlo Risk Simulation, Strategic Real Options, Stochastic Forecasting, Portfolio Optimization, Data Analytics, Business Intelligence, and Decision Modeling (Third Edition: Thompson-Shore, 2015; Second Edition: Wiley Finance, 2010).

[13] Mun, Johnathan. Real Options Analysis: Tools and Techniques (Third Edition: Thompson Shore, 2016; Second Edition: Wiley Finance, 2010).

[14] Naval Sea Systems Command (NAVSEA). (2015). Cost estimating. In SUPSHIP Operations Manual (SOM) (NAVSEA S0300-B2-MAN-010; ch. 6). Washington, DC: Department of the Navy.

[15] Ross, J. M. (n.d.) A practical approach for ship construction cost estimating. Retrieved from http://ds-t.com/trade_show s-cd/ProteusEngineeringCOMPITPaper2004.pdf

[16] Smith, M. B. (2008). Updating MIT’s cost estimation model for shipbuilding (Master's thesis). Cambridge, MA: Massachusetts Institute of Technology.

[17] SPAR Associates. (2015). Independent cost estimating services [Presentation]. Retrieved fromhttp://www.sparusa .com/Presentations/Independent\%20Cost\%20Estimating\% 20Services-Overview.pdf

[18] Truver, S. C. (2001, January-February). Navy develops product-oriented design and construction cost model: PODAC emerges as critical element in achieving operationally superior, affordable naval forces. Program Manager, 38-41.

[19] Walcott, J. (2012). Budget Office questions Navy shipbuilding cost estimates. Bloomberg. Retrieved from http://www.bloomberg.com/news/articles/2012-07-25/bud get-office-questions-navy-shipbuilding-cost-estimate 